\title{
Force Measurement-Based Discontinuity Detection during Friction Stir Welding
}

\author{
Amber Shrivastava, ${ }^{1}$ Michael Zinn, ${ }^{1}$ Neil A. Duffie, ${ }^{1}$ Nicola J. Ferrier, ${ }^{2}$ \\ Christopher B. Smith, ${ }^{3}$ and Frank E. Pfefferkorn ${ }^{1 *}$ \\ ${ }^{I}$ The University of Wisconsin-Madison, Madison, WI, U.S.A. \\ ${ }^{2}$ Argonne National Laboratory, Lemont, IL, U.S.A. \\ ${ }^{3}$ Wolf Robotics LLC, Fort Collins, CO, U.S.A. \\ ashrivastav3@wisc.edu, mzinn@wisc.edu,duffie@engr.wisc.edu,nferrier@anl.gov, \\ csmith@wolfrobotics.com, frank.pfefferkorn@wisc.edu
}

\begin{abstract}
The objective of this work is to develop a method for detecting the creation of discontinuities (i.e., voids, volume defects) during friction stir welding. Friction stir welding is inherently cost effective, however, the need for significant weld inspection can make the process cost prohibitive. A new approach to weld inspection is required in which an in-situ characterization of weld quality can be obtained, reducing the need for post-process inspection. To this end, friction stir welds with subsurface voids and without voids were created. The subsurface voids were generated by reducing the friction stir tool rotation frequency and increasing the tool traverse speed to create "colder" welds. Process forces were measured during welding, and the void sizes were measured post-process by computerized tomography (i.e., 3D X-ray imaging). Two parameters, based on frequency domain content and timedomain average of the force signals, were found to be correlated with void size. Criteria for subsurface void detection and size prediction were developed and shown to be in good agreement with experimental observations. With the proper choice of data acquisition system and frequency analyzer the occurrence of subsurface voids can be detected in real time.
\end{abstract}

Keywords: Friction Stir Welding, Discontinuity detection, Force measurement, Aluminum

(C) 2017. This manuscript version is made available under the Elsevier user license

http://www.elsevier.com/open-access/userlicense/1.0/ 


\title{
Nomenclature
}

\author{
$\underline{\text { Symbols }}$ \\ $\mathrm{dp} \quad$ Probe diameter [mm] \\ f Feed rate $[\mathrm{mm} / \mathrm{min}]$ \\ Fy $\quad$ Force in weld direction $[\mathrm{N}]$ \\ Fy-av $\quad$ Average force in weld direction $[\mathrm{N}]$ \\ $\mathrm{Fy}_{1}^{3} \quad 3 \mathrm{rd}$ harmonic of $\mathrm{y}$-force normalized by $1^{\text {st }}$ harmonic of $\mathrm{y}$-force [-] \\ $\mathrm{Fy}_{\mathrm{Av}}^{3} \quad 3 \mathrm{rd}$ harmonic of $\mathrm{y}$-force normalized by average $\mathrm{y}$-force [-] \\ hp Probe height [mm] \\ $\mathrm{n} \quad$ Number of flats on the friction stir tool [-] \\ $\mathrm{V}_{\mathrm{Sz}}^{\mathrm{D}} \quad$ Discontinuity volume per revolution normalized by probe stir zone volume [-] \\ $\underline{\text { Greek Symbols }}$ \\ $\omega \quad$ Rotation frequency [ $\mathrm{rad} / \mathrm{sec}]$ \\ Acronyms \\ APR Advance per revolution ( $\mathrm{mm} / \mathrm{rev})$ \\ CT Computerized tomography \\ DAQ Data acquisition \\ FFT Fast Fourier transform \\ FS Friction stir \\ FSW Friction stir welding \\ ROI Region of interest \\ TWI The welding institute
}

\section{Introduction}

Friction stir welding (FSW) was invented at The Welding Institute in the United Kingdom (Thomas et al. 1991, 1995). This relatively new joining process differs from most other welding processes by typically not melting the workpiece. As a result, the joining process is energy efficient, environment friendly, and versatile and generates high-quality joints.

FSW is a metal joining process in which two or more components are plastically deformed and mechanically intermixed under mechanical pressure at elevated temperatures (Mishra and Ma, 2005; Threadgill et al., 2009). However, these joints are created at or below the solidus temperature of the workpiece, making FSW a solid-state welding process. Figure 1 shows a schematic of the FSW process for a butt weld. The process involves a nonconsumable rotating friction stir (FS) tool, with a specifically designed probe (pin) and shoulder, which is plunged with a downward force into the workpiece. Once the probe is completely inserted in the workpiece and the shoulder makes contact with the surface, the FS tool is traversed along the weld seam (butt welding) or defined path (lap welding, bead-on-plate, friction stir processing). At the end of the weld the FS tool is retracted. Initially, the FS tool generates heat due to friction, which facilitates plastic deformation of the parent material (i.e., stirring). Once the material is being plastically deformed in the stir zone, heat is generated due to friction and heat dissipation due to plastic deformation. The plasticized material is mixed and extruded past the FS tool, after which it is forged together in the wake of the FS tool. Friction stir welding results in intense plastic deformation at elevated temperature in the weld zone, which leads to significant microstructural evolution, for example, grain refinement (Mishra and Ma, 2005; Threadgill et al., 2009). 


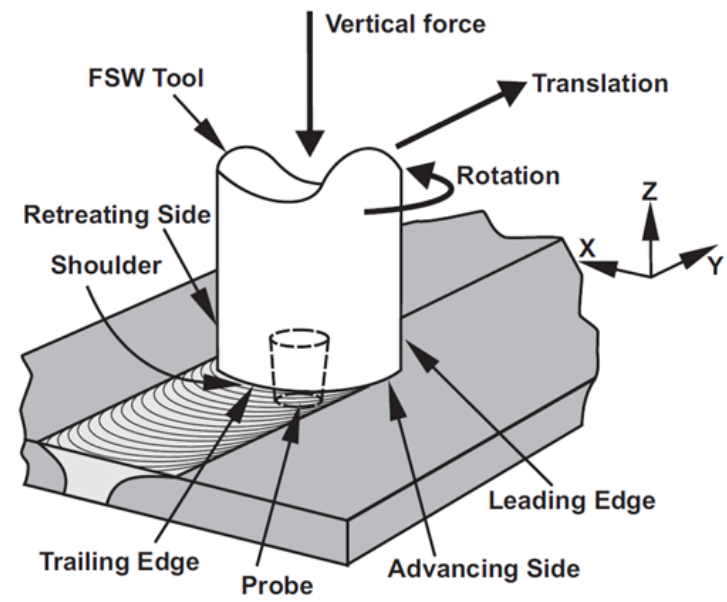

Figure 1: Schematic of friction stir [butt] welding showing global coordinate system of forces acting on the FS tool

The advantages of FSW are significant and include energy savings, superior mechanical joint properties, and lower process environmental impact as compared with fusion welding processes. While the creation of a friction stir weld can be cost effective, the need for significant weld inspection, particularly in the case of high-reliability applications, can increase the cost by a factor of 3 or more, making it cost prohibitive. Therefore, a new approach to weld inspection is required where an in situ characterization of weld quality can be obtained, significantly reducing the need for post-process inspection.

Boldsaikhan et al. (2011) presented a real-time approach for detecting continuous-void discontinuities in FSW in a nondestructive manner. A discrete Fourier transform and a multilayer neural network were used for evaluating the feedback forces observed during FSW. Fleming et al. (2008) investigated methods for implementing in-process fault avoidance in robotic FSW. They showed that statistical methods can be used as a prestep to derive representations of force data that provide good insight into the state of the on-going weld. Burford et al. (2012) used an e-NDE technique based on monitoring the force feedback signals that were previously correlated with the discontinuity formation. Their work showed promising results for increasing the accuracy and precision of probability of detection analyses when compared with conventional inspection techniques. Singh and Hamilton (2009) assessed FSW quality through dynamic characterization. Modal parameters were measured and correlated with the physical parameters of the welded components such as axial and flexural rigidities. The authors showed that the assessment of weld quality of FSW beams using dynamic interrogation techniques is viable.

Chen et al. (2006) investigated the formation of the discontinuities in 5456 aluminum alloy friction stir welds. Based on the microscopic examination of the nugget zone and the fracture location of the weld, the authors suggested that the tilt angle can change the plastic material flow pattern in the stir zone. They also suggested that the $\mathrm{Al}_{2} \mathrm{O}_{3}$ particles from initial butt surface are the major cause of the failure of the joints. Khan et al. (2015) investigated the effect of FS tool probe offset and plunge depth on the formation of tunneling discontinuities and kissing bonds in friction stir welds with dissimilar alloys (AA5083-H116 and AA6063-T6). The authors reported that tunneling and kissing bond defects were formed in welds with the FS tool probe offset toward the stronger alloy. The size of the tunneling discontinuity decreased significantly by increasing the plunge depth. Kumar et al. (2015) discussed discontinuity detection during FSW using discrete wavelet transform of force and torque signals. Their work showed that the discontinuities present in friction stir welds produce sudden changes in the 
features of the force signals. The statistical tool known as square of errors, when implemented on the discrete wavelet transform coefficients, localized the abrupt changes more evidently. Ramulu et al. (2013) analyzed the effect of welding speed, rotation speed, plunge depth, and shoulder diameter on the formation of internal discontinuities during FSW. Friction stir welds created with $2.1 \mathrm{~mm}$ thick Al 6061-T6 alloy were investigated in that work. As a criterion for identifying the onset of a discontinuity-free weld region, the authors proposed observing the change in axial force and torque with respect to welding parameters.

Rosado et al. (2010) used an eddy current probe based non-destructive testing system focusing on micro size superficial discontinuities in metallic friction stir welds. The testing results showed that the system was able to detect superficial discontinuities less than $60 \mu \mathrm{m}$ deep. This method predicts only superficial voids, however, and does not predict the subsurface discontinuities deeper than $60 \mu \mathrm{m}$. Santos et al., (2014) presented a concept of FSW assisted by an electric oule effect. This was aimed at minimizing the root discontinuities (lack of penetration) in friction stir welds. Experimental results showed that passing an electrical current through the weld root can significantly reduce the lack of penetration discontinuity. Weld macrographs were made for visualizing the discontinuities. This method allows mitigation of a common discontinuity in FSW: root defect. However, it does not facilitate the detection or estimation of the discontinuity sizes. Zhang et al., (2012) examined the characteristics of discontinuities in underwater friction stir welds and investigated the formation mechanism of the discontinuities. After welding, joints were cross-sectioned perpendicular to the weld direction, and the weld cross-sections were imaged via light microscopy. The authors observed that at relatively high rotation speeds and low welding speed (feed), the material beneath the shoulder tends to be extruded into the probe stirred zone after flowing back to the advancing side. An unstable flow condition results, creating discontinuities in the probe stirred zone. Shrivastava et al. (2015) presented an FSW dynamic force model and discontinuity model for predicting forces and discontinuities during friction stir welding. The weld joints were cross-sectioned and imaged for confirming and measuring the discontinuities. Experimental results showed that the welds with discontinuities are accompanied by higher force amplitudes at higher harmonics corresponding to the number of flats on the FSW tool in addition to the tool rotation frequency.

Yasui et al. (2014) performed dissimilar friction stir welds of aluminum alloy (Al 6061) and steel (S45C). The distribution and size of the steel chips in the weld were studied with an X-ray computerized tomography (CT) method. The macrostructures and CT results were presented for welds without defects. Their work provided direct evidence of the material movement due to the dissimilar nature of the welds and three-dimensional information captured from CT data. However, information regarding any discontinuity formed during FSW was missing. Morisada et al. (2015) used a real-time X-ray imaging system to obtain three-dimensional flow patterns during FSW of Aluminum 1050 plates. The tungsten tracer was used to track the material movement. In that study, X-rays could transmit through workpiece material, backing plate material, and tool material. X-rays were blocked only by the tungsten tracer. A concentric material flow zone was reported around the probe under the optimal FSW conditions. However, any discontinuity formed during FSW was not visible in X-ray images because the X-rays would transmit through all but the tungsten tracer. Edwards and Ramulu (2015) carried out a friction stir weld of $6 \mathrm{~mm}$ thick Ti-6Al-4V butt joints with a tracer material embedded in the joint. The material flow pattern in these welds was established by examining postweld X-ray radiographs. That work also made no comments about the discontinuity formation during FSW. To date, all the works that have included CT X-ray for analysis in FSW have focused on studying material flow.

Researchers have explored different types of discontinuities formed during FSW and associated formation mechanisms. Efforts also have been made to detect these discontinuities by measuring various parameters such as force, torque, and temperature during FSW. However, the relationship between measured quantities and discontinuity sizes is missing. Among most of the explored methods for discontinuity detection, discontinuities can be detected without any prediction of the discontinuity 
size. Our work focuses on detecting discontinuities by measuring forces during FSW. Our main objective is to develop a relationship between the force transients and the discontinuity sizes. This will enable the detection of discontinuity and prediction of the discontinuity size at the same time.

\section{Experimental Methods}

The friction stir welds were performed on a commercial 3-axis CNC mill (HAAS TM-1). The spindle motor's maximum rating is $5.6 \mathrm{~kW}$, the maximum spindle torque is $45 \mathrm{Nm}$, and the maximum spindle speed is $4,000 \mathrm{rpm}$. The FS tool travel angle was held constant at 3 degrees for all the welds. FS tools made of $\mathrm{H} 13$ tool steel with a concave shoulder and a threaded, conical probe with flats were used. The FS tool shoulder diameter was $15 \mathrm{~mm}$, and the probe diameter tapered from 7 to $5.4 \mathrm{~mm}$. The FS tool probe was $4 \mathrm{~mm}$ long. Workpieces were $203 \mathrm{~mm}$ long, $102 \mathrm{~mm}$ wide, and $4.76 \mathrm{~mm}$ thick Aluminum 6061-T6 alloy. Weld parameters that were held constant throughout the experiments are listed in Table 1.

Advance per revolution (APR) is the ratio of feed/weld rate $(\mathrm{mm} / \mathrm{min})$ and spindle speed (RPM) of FS tool during a friction stir weld and has units of $\mathrm{mm} / \mathrm{rev}$. Welds were performed at five different APRs: $0.78,0.83,0.89,0.94$, and $1.00 \mathrm{~mm} / \mathrm{rev}$. For each APR, spindle speed was varied from 600 $\mathrm{rev} / \mathrm{min}$ to $1000 \mathrm{rev} / \mathrm{min}$ in steps of $100 \mathrm{rev} / \mathrm{min}$. These weld parameters are known to produce friction stir welds with discontinuities (i.e., volume defects). Table 2 shows the feed rate corresponding to each APR and rotation speed (RPM) combination for the welds with discontinuities. Beside these 25 welds, 7 welds were performed at conditions known to produce friction stir welds without discontinuities. Table 3 shows the rotation speed and feed rate for the welds without discontinuities. Additional friction stir welds were created in order to validate the discontinuity detection method developed in this work. These welds are discussed in Section 4. Welding forces were measured by using a 3-axis force dynamometer (Kistler model 9265). The FS tool was zeroed in the z-direction (Figure 1) with respect to the FS tool shoulder. 
Table 1: Weld parameters that were held constant throughout the experiments

\begin{tabular}{lc}
\hline Type of Weld & Butt Weld \\
\hline Workpiece material & $6061-\mathrm{T} 6$ aluminum \\
Workpiece dimensions & $203 \times 102 \times 4.76 \mathrm{~mm}$ \\
Backing plate material & Mild steel \\
\hline Travel angle & $3^{\circ}$ \\
Work angle & $0^{\circ}$ \\
Gap & None \\
Plunge depth & $0.2 \mathrm{~mm}$ \\
Weld length & $175 \mathrm{~mm}$ \\
\hline FS Tool material & H13 tool steel \\
FS Tool shoulder: concave angle & $3^{\circ}$ \\
FS Tool shoulder: dia. & $15 \mathrm{~mm}$ \\
FS Tool probe: conical angle $(2 \theta)$ & $22.6^{\circ}$ \\
FS Tool probe: major dia. & $7 \mathrm{~mm}$ \\
FS Tool probe: minor dia. & $5.4 \mathrm{~mm}$ \\
FS Tool probe: length & $4 \mathrm{~mm}$ \\
FS Tool probe: thread pitch & $1.588 \mathrm{~mm}$ \\
\hline
\end{tabular}

Since the FS tool shoulder cannot contact the workpiece top surface (because of the FS tool probe: 4 $\mathrm{mm}$ height) directly, a $7.62 \mathrm{~mm}$ precision gage-block was placed between the trailing edge of the FS tool and the top surface of the workpiece. Then the FS tool was lowered with minimum increment $(0.001 \mathrm{~mm})$ setting in the z-axis, to achieve a defined preload of $20 \mathrm{~N}$ in z-direction. This ensured complete contact between the workpiece-precision gage and precision gage-FS tool shoulder interfaces. This method eliminates the inconsistencies in zeroing the z-axis, which results in inconsistent plunge depth between friction stir welds.

Table 2: Feed rate corresponding to each APR and RPM combination for welds with discontinuities (all welds were performed using FS tool with 3 flats on the probe)

\begin{tabular}{cccccc}
\hline & \multicolumn{5}{c}{ APR (mm/rev) } \\
\cline { 2 - 6 } $\begin{array}{c}\text { RPM } \\
\text { (rev/min) }\end{array}$ & 0.78 & 0.83 & 0.89 & 0.94 & 1.00 \\
\hline 600 & 467 & 500 & 533 & 567 & 600 \\
700 & 544 & 583 & 622 & 661 & 700 \\
800 & 622 & 667 & 711 & 756 & 800 \\
900 & 700 & 750 & 800 & 850 & 900 \\
1000 & 778 & 833 & 889 & 944 & 1000 \\
\hline
\end{tabular}

Table 3: Rotation speed and feed rate for the welds without discontinuities

\begin{tabular}{cccc}
\hline $\begin{array}{c}\text { Serial } \\
\text { No. }\end{array}$ & $\begin{array}{c}\text { RPM } \\
(\mathrm{rev} / \mathrm{min})\end{array}$ & $\begin{array}{c}\text { Feed } \\
(\mathrm{mm} / \mathrm{min})\end{array}$ & $\begin{array}{c}\text { No. of FS } \\
\text { tool flats }\end{array}$ \\
\hline 1 & 1100 & 400 & 3 \\
2 & 1100 & 500 & 3 \\
3 & 1300 & 300 & 3 \\
4 & 1300 & 400 & 3 \\
5 & 1300 & 500 & 3 \\
6 & 1500 & 400 & 3 \\
7 & 1500 & 500 & 3 \\
\hline
\end{tabular}


One $20 \mathrm{~mm}$ wide and $45 \mathrm{~mm}$ long specimen was cut from each weld. Each specimens was cut such that it included a small part of the exit hole. Figure 2 shows an image of a representative specimen. CT scans of these specimens were performed on a Siemens microCATII scanner. The 3D dataset from CT scans was analyzed by using "Inveon Research Workplace" software. The voxel size of the CT scan was $34 \mu^{3}$. For consistency, a $20 \mathrm{~mm}$ long region of interest (ROI) at a distance of $5 \mathrm{~mm}$ from the last shoulder mark was defined for each specimen. Figure 3 shows a representative section. The CT scan datasets from all the welds were analyzed with same threshold values (-800 to 1225 Hounsfield units). The analysis of the CT scan dataset from each weld specimen provided the total discontinuity volume $\left(\mathrm{mm}^{3}\right)$ present in the ROI. The force data (along the weld direction: y-direction, Fig. 1) corresponding to the $20 \mathrm{~mm}$ long ROI was identified. Figure 4 shows the complete force data and section of force data corresponding to the ROI for a representative friction stir weld. Average force and force amplitudes for the first five harmonics (of the tool rotation frequency) were evaluated for each friction stir weld.

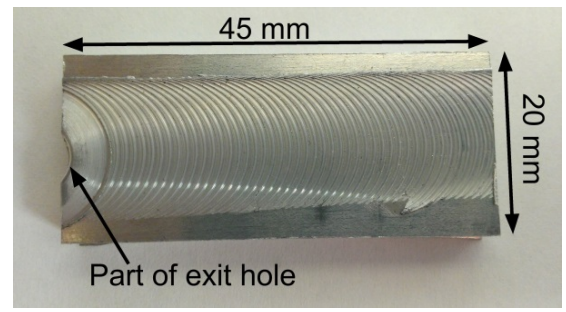

Figure 2: Image of a representative specimen for CT scan

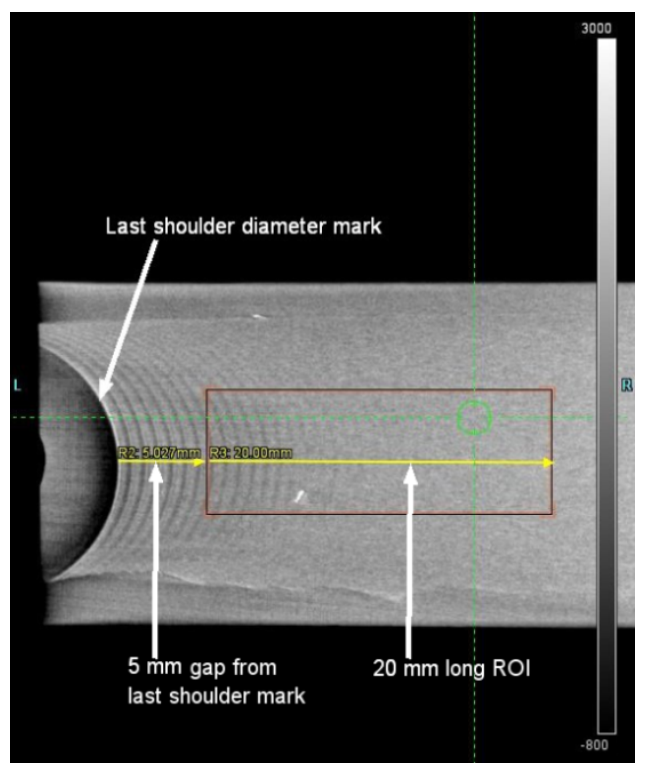

Figure 3: ROI section defined for a representative CT scan data set 


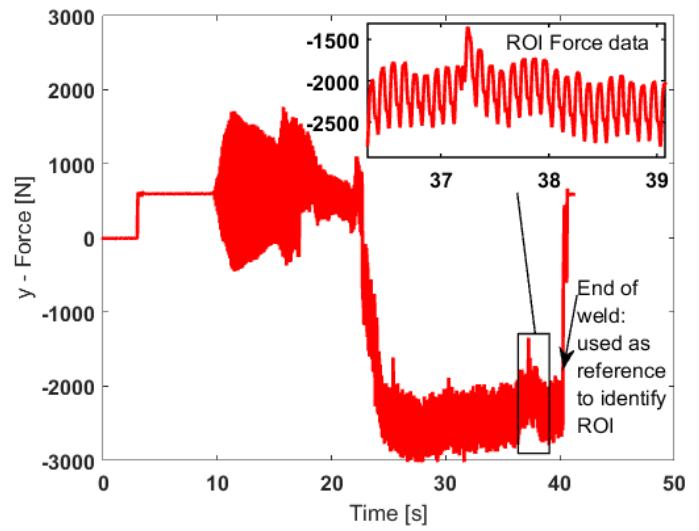

Figure 4: Complete force data (along y-direction) and section of force data corresponding to the ROI for a representative friction stir weld

\section{Results}

The CT datasets of the friction stir weld specimens were analyzed to obtain the total volume of discontinuities present in the ROI section of each specimen. The discontinuities are formed as the frictions stir weld progresses, i.e., with each revolution of friction stir tool during traverse phase. The average discontinuity volume formed per revolution was estimated for each weld (total discontinuity volume x APR / ROI length). Also, different force-parameters like average force, force amplitude at tool rotation frequency and higher harmonics, were discerned from the force data captured during the friction stir welds. Next, the relationship between the average discontinuity volume formed per revolution and different force-parameters from the force data was studied by plotting the average discontinuity volume against the force parameters. At first no direct relationship between the average discontinuity volumes and the force parameters was observed. Next, the relationship between the ratio of different force parameters and the ratio of discontinuity volume per revolution and probe stir zone volume ( $\pi \mathrm{x}$ average probe radius $\mathrm{x}$ probe height $\mathrm{x}$ APR) was investigated. The third harmonic of the $y$-force normalized by the average $y$-force $\left(\mathrm{Fy}_{\mathrm{Av}}^{3}\right)$ showed a consistent linear relationship with the discontinuity volume per revolution normalized by the probe stir zone volume $\left(\mathrm{V}_{\mathrm{Sz}}^{\mathrm{D}}\right)$ for the welds with discontinuities (Figure 5). This result suggests that a linear relationship between $\mathrm{Fy}_{\mathrm{Av}}^{3}$ and $\mathrm{V}_{\mathrm{Sz}}^{\mathrm{D}}$ can be used for estimating the discontinuity size.

In this work, a normalized parameter's symbol is accompanied with a subscript and a superscript. The subscript represents the "normalized by" parameter or the denominator, and superscript represents the "normalized" parameter or the numerator. For example, $\mathrm{Fy}_{\mathrm{Av}}^{3}$ is the third harmonic of the forces in the $y$-direction normalized by the average force in the y-direction. Similarly, $V_{S z}^{D}$ is the discontinuity volume formed per revolution normalized by the probe-stir zone volume. Figure 6 shows the plot of $\mathrm{Fy}_{\mathrm{Av}}^{3}$ vs $\mathrm{V}_{\mathrm{Sz}}^{\mathrm{D}}$ for all the welds (with and without discontinuities: Tables 2 and 3). It can be noticed from the figure that the range (min-max) of the magnitude of $\mathrm{Fy}_{\mathrm{Av}}^{3}$ for welds without discontinuities $(0.025$ - 0.074) is also appreciable and comparable to the range of the magnitude of $\mathrm{Fy}_{\mathrm{Av}}^{3}$ for welds with discontinuities $(0.031-0.102)$. This result suggests that $\mathrm{Fy}_{\mathrm{Av}}^{3}$ cannot be used for differentiating between welds with and without discontinuities.

Figure 7 shows the plot of $\mathrm{Fy}_{1}^{3} \mathrm{vs} \mathrm{V}_{\mathrm{Sz}}^{\mathrm{D}}$ for all the welds (with and without discontinuities: Tables 2 and 3). One can see that $\mathrm{Fy}_{1}^{3}$ for welds with discontinuities does not indicate any trend with respect to $\mathrm{V}_{\mathrm{Sz}}^{\mathrm{D}}$. This result suggests that a relationship between $\mathrm{Fy}_{1}^{3}$ and $\mathrm{V}_{\mathrm{Sz}}^{\mathrm{D}}$ cannot be effectively used for estimating discontinuity sizes for the welds with discontinuities. However, $\mathrm{Fy}_{1}^{3}$ for welds without 
discontinuities is distinctly smaller than $\mathrm{Fy}_{1}^{3}$ for the welds with discontinuities. This distinction in $\mathrm{Fy}_{1}^{3}$ can be used for distinguishing between welds with and without discontinuity.

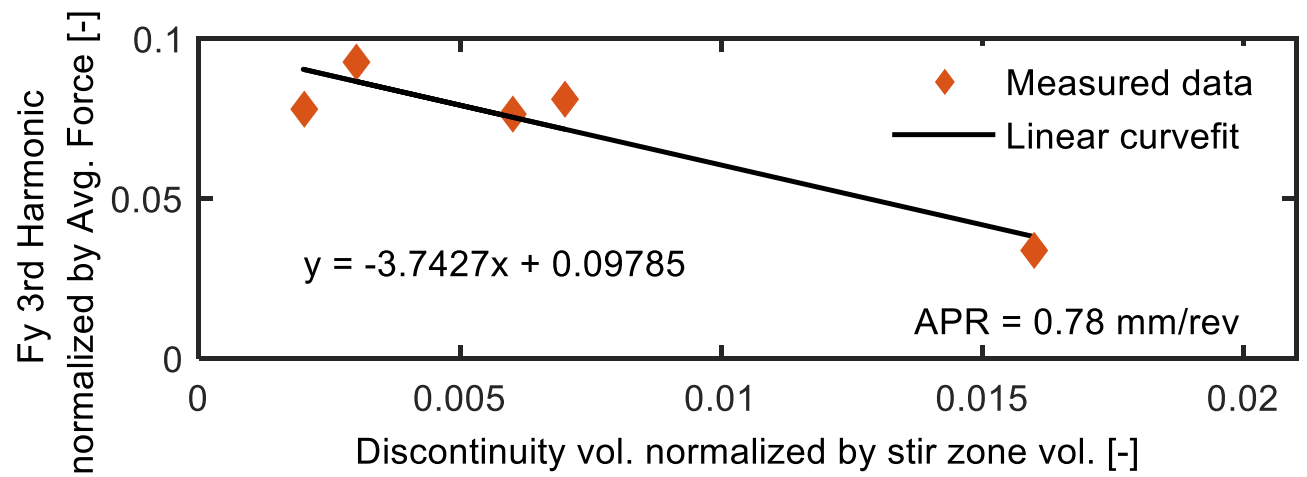

(a)

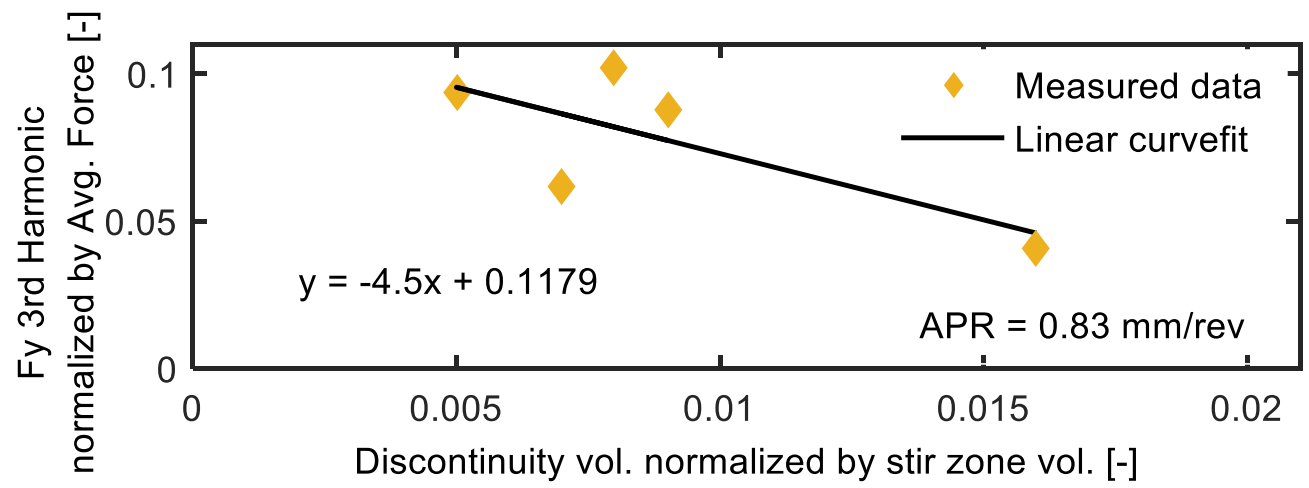

(b)

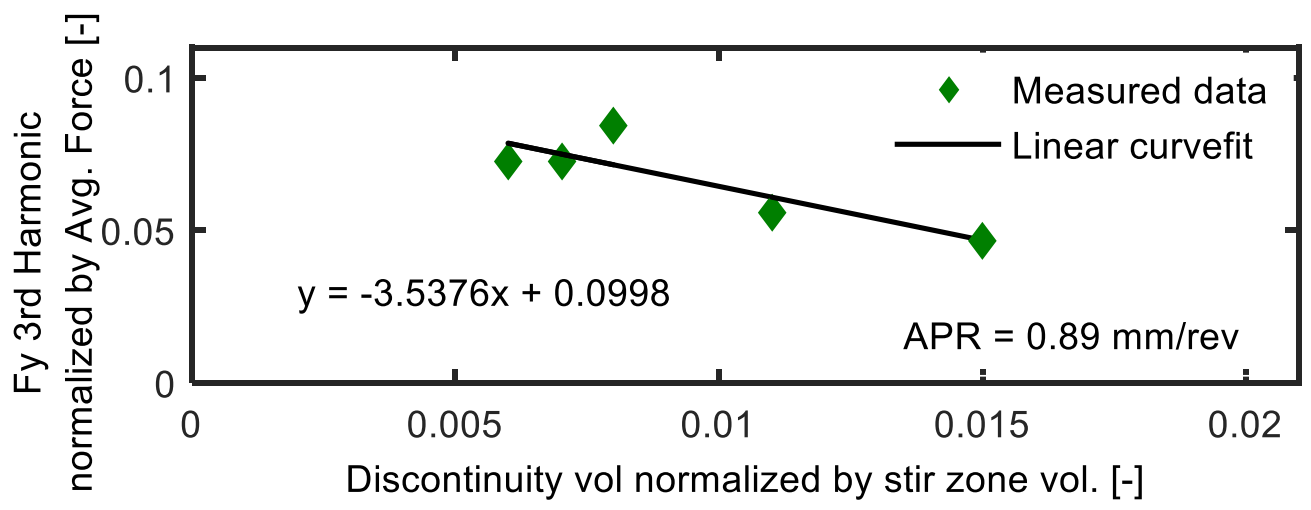

(c) 


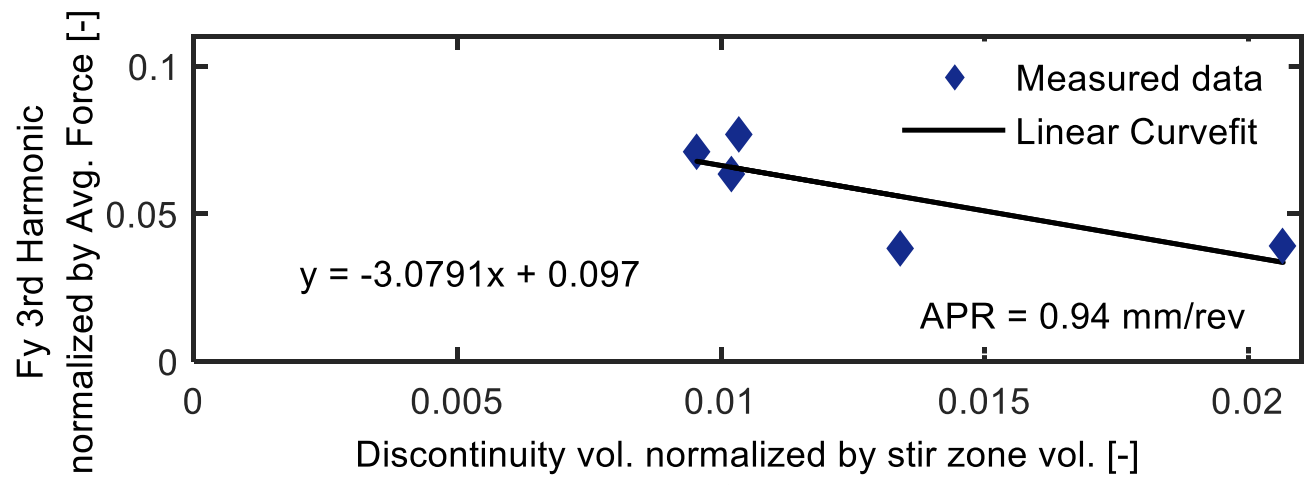

(d)

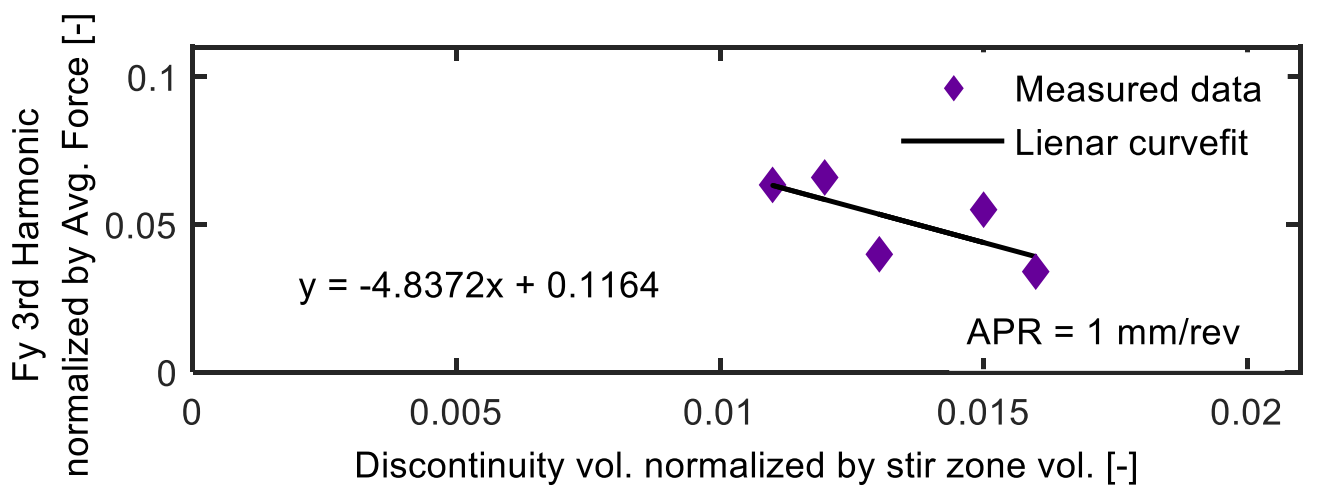

(e)

Figure 5: $\mathrm{Fy}_{\mathrm{Av}}^{3}$ as a function of $\mathrm{V}_{\mathrm{Sz}}^{\mathrm{D}}$ for the welds with discontinuities performed at (a) $0.78 \mathrm{~mm} / \mathrm{rev}$ APR (b) $0.83 \mathrm{~mm} / \mathrm{rev}$ APR (c) $0.89 \mathrm{~mm} / \mathrm{rev}$ APR (d) $0.91 \mathrm{~mm} / \mathrm{rev}$ APR (e) $1 \mathrm{~mm} / \mathrm{rev}$ APR (marker colors correspond to the APRs in Table 2)

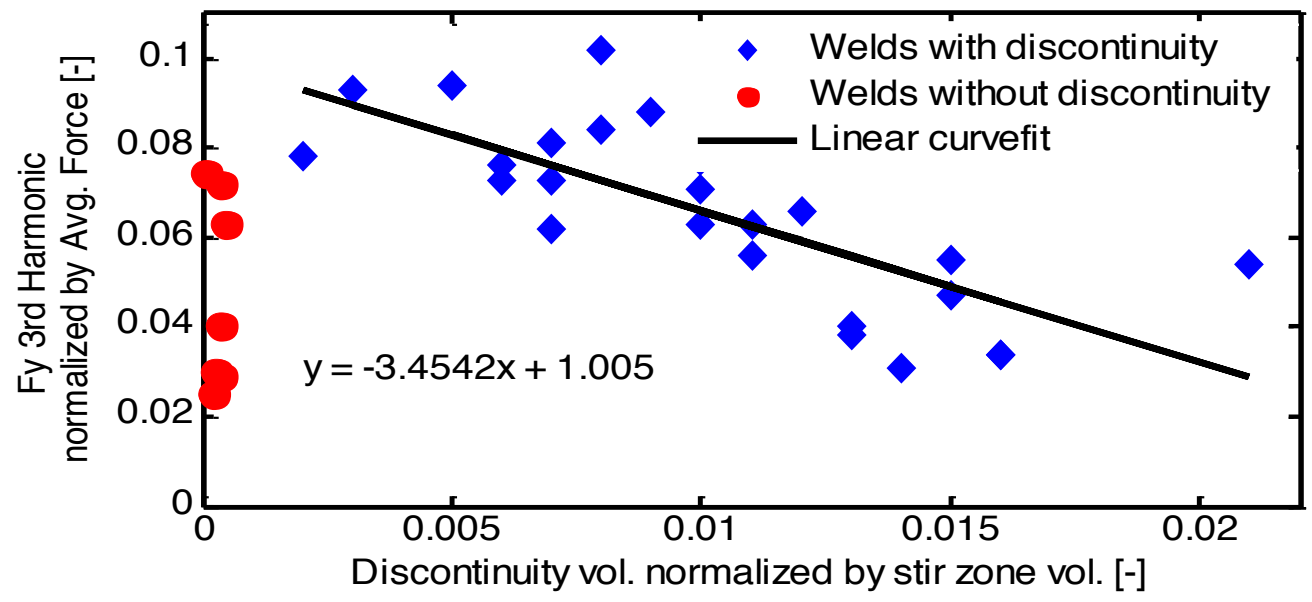

Figure 6: $\mathrm{Fy}_{\mathrm{Av}}^{3}$ as a function of $\mathrm{V}_{\mathrm{Sz}}^{\mathrm{D}}$ for the welds with and without discontinuities 


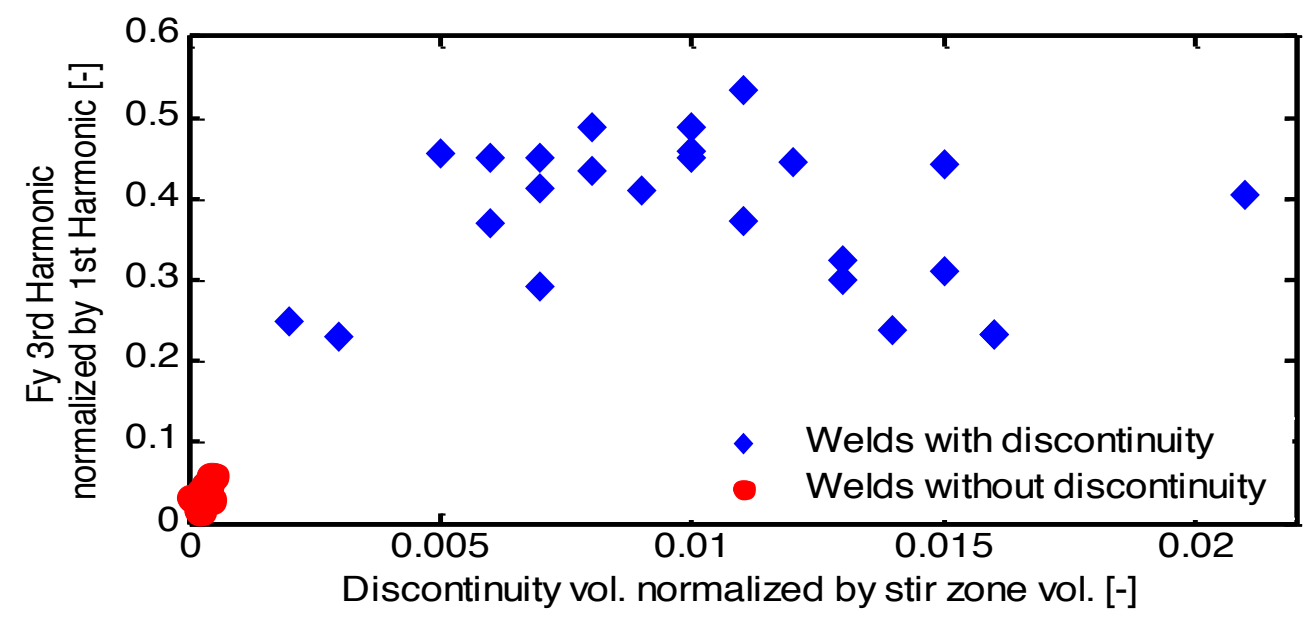

Figure 7: $\mathrm{Fy}_{1}^{3}$ as a function of $\mathrm{V}_{\mathrm{Sz}}^{\mathrm{D}}$ for the welds with and without discontinuities

\section{Discussion}

In this paper, welds with discontinuity were created by increasing the feed rate and reducing the spindle rotation speed. The reduction in spindle rotation speed causes reduced heat generation in the weld. This results in a relatively lower weld temperature than the temperature required for a weld without discontinuity (performed at nominal feed and spindle speed). The reduced temperature makes it difficult to plastically deform the material and move/stir the material around the tool, thus increasing the resistance offered by the material to the FS tool movement in the weld direction. As a result the average force experienced by the FS tool in the weld direction increases. More aggressive conditions (higher feed rate and reduced spindle speed) resulted in the formation of larger discontinuities in the stir zone volume. These conditions also contribute towards higher average force in the weld direction. This is evident from the negative slope of the linear trend line (for welds with discontinuities) in Figure 6. In that figure, as the ratio of the discontinuity volume to the stir zone volume $\left(\mathrm{V}_{\mathrm{Sz}}^{\mathrm{D}}\right.$, along the $\mathrm{x}$-axis) increases, the average force in the weld direction increases. This explains an overall reduction in the ratio of the Fy third harmonic amplitude to the average force in the weld direction $\left(\mathrm{Fy}_{\mathrm{Av}}^{3}\right)$. The mean value of the "average force in the weld direction" for all the welds without discontinuities is 235 $\mathrm{N}$. Whereas, the mean value of the "average force in the weld direction" for all the welds with discontinuities, is $1776 \mathrm{~N}$. However, it is interesting to note that, in Figure 6, the magnitude of $\mathrm{Fy}_{\mathrm{Av}}^{3}$ for welds without discontinuities compares well with the $\mathrm{Fy}_{\mathrm{Av}}^{3}$ for the welds with discontinuities. This observation can be explained based on the difference in the magnitude of the Fy third harmonic amplitude between the welds with and without discontinuities. The mean value of the Fy third harmonic amplitude for all the welds without discontinuities is $11 \mathrm{~N}$. Whereas, the mean value of the Fy third harmonic amplitude for all the welds with discontinuities, is $109 \mathrm{~N}$. For the welds with discontinuities, the relatively higher magnitude of Fy third harmonic amplitude is attributed to the discontinuities formed in the stir zone (discussed later in this section).

$\mathrm{Fy}_{\mathrm{Av}}^{3}$ captures the effect of this difference in weld conditions as well as the discontinuity formation during welding. It is important to account for the difference in the weld conditions, as the welds with and without discontinuities were performed with different weld parameters (Tables 2 and 3), and a change in a given metric can be either due to different weld conditions or due to discontinuity formation. This result gives trust in the relationship between $\mathrm{Fy}_{\mathrm{Av}}^{3}$ and $\mathrm{V}_{\mathrm{Sz}}^{\mathrm{D}}$ for the welds with discontinuities. However, the range of the magnitude of $\mathrm{Fy}_{\mathrm{Av}}^{3}$ for welds without discontinuities is also 
appreciable and comparable to the range of the magnitude of $\mathrm{Fy}_{\mathrm{Av}}^{3}$ for welds with discontinuities (Figure 6). Therefore, $\mathrm{Fy}_{\mathrm{Av}}^{3}$ cannot be used for differentiating between welds with and without discontinuities.

In a previous work (Shrivastava et al., 2015), experimental results suggested that the welds with discontinuities are accompanied by higher force amplitudes at higher harmonics corresponding to the number of flats on the FSW tool in addition to the tool rotation frequency. The process force oscillations at higher harmonics originate from the interaction of the discontinuities with flats on the FSW tool probe. That is, the FSW tool experiences additional force components every time an FSW tool probe flat passes through the region where the discontinuity is being formed. The force magnitude at the higher harmonics (corresponding to the number of flats) will depend on the size of the discontinuity, morphology of the discontinuity, and weld parameters. All these parameters varied across the experiments reported here, resulting in the scatter in the $\mathrm{Fy}_{1}^{3}$ data shown in Figure 7.

To explain the scatter in Figure 7, consider Figure 8, which shows two extremely different discontinuity morphologies observed among the welds with discontinuities. These discontinuities are at the depth of $2.4 \mathrm{~mm}$ (half of the workpiece height) from the top surface of the workpiece. In Figures 8(a) and 8(b) discontinuities are present in the advancing side. In Figure 8(a), the discontinuities have the form of a stack of arcs aligned in the weld direction. In Figure 8(b), the discontinuity looks like a continuous trench. However, a closer look at the discontinuities reveals not-so-pronounced arc-shaped features preceding the trench. Further investigation confirmed the formation and filling of a cavity by the material once per revolution at the rear of the tool, resulting in the oscillation of the forces in the ydirection at the tool rotation frequency (first harmonic). The magnitude of the Fy oscillations at the tool rotation frequency will be decided by the amount of the material rotated around the FS tool per revolution. The maximum size of the discontinuity formed per revolution in this work was about $2 \%$ of the probe stir zone volume. This should minimally affect the force amplitudes at the tool rotation frequency. A comparison shows that the mean value of the Fy first harmonic amplitude for welds with discontinuities is $295 \mathrm{~N}$ (with standard deviation of $53 \mathrm{~N}$ ) and without discontinuity is $298 \mathrm{~N}$ (with standard deviation of $36 \mathrm{~N}$ ). Therefore, $\mathrm{Fy}_{1}^{3}$ essentially represents the variation in the Fy third harmonic amplitude (Figure 7). Despite the scatter in $\mathrm{Fy}_{1}^{3}$ for the welds with discontinuity in Figure 7, $\mathrm{Fy}_{1}^{3}$ for welds without discontinuities is distinctly smaller than $\mathrm{Fy}_{1}^{3}$ for welds with discontinuities. This distinction in $\mathrm{Fy}_{1}^{3}$ can be used for distinguishing between welds with and without discontinuity. It is believed that a normalized Fy third harmonic metric $\left(\mathrm{Fy}_{1}^{3}\right)$ would be better applicable across different FS tool designs and weld conditions.

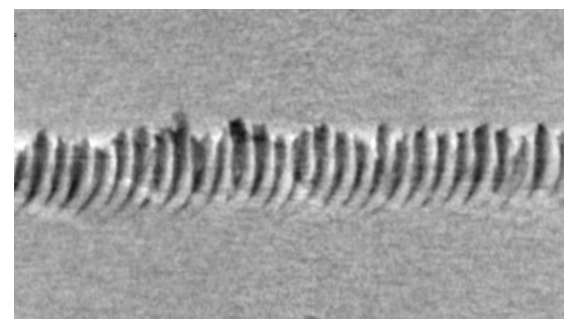

(a)

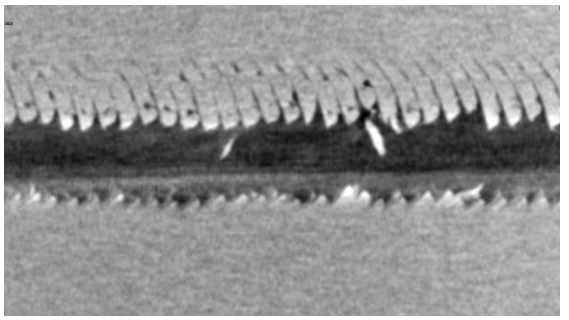

(b)

Figure 8: Images from CT scans of two representative friction stir weld regions of interest: (a) discontinuities in the form of sub-surface stack of arcs $(900 \mathrm{rpm} \& 700 \mathrm{~mm} / \mathrm{min})$, and (b) discontinuities in form of a subsurface continuous trench $(1000 \mathrm{rpm} \& 1000 \mathrm{~mm} / \mathrm{min})$. Field of view $=$ $16 \mathrm{~mm} \times 8.8 \mathrm{~mm}$ and image plane is $2.4 \mathrm{~mm}$ below the surface. 


\subsection{Discontinuity detection method \& validation}

Based on the findings of this work, authors propose a discontinuity detection method (Figure 9). This method takes into consideration the FS tool design (number of flats, probe diameter, and probe height) and weld parameters (spindle rotation speed and feed rate). Forces along the weld direction (Fy) are used as the input to the method. Advances per revolution, tool rotation frequency, Fy amplitude corresponding to tool rotation frequency, Fy amplitude at the harmonic corresponding to the number of flats on the FS tool, and average Fy are discerned from the available information. Next, the ratio of the Fy third harmonic amplitude to the Fy first harmonic amplitude are compared with a threshold value of 0.2 (from Figure 7). If the ratio is smaller than the threshold value, the weld is evaluated as a "weld without discontinuity." Otherwise, the weld is evaluated as a "weld with discontinuity," and the size of the discontinuity formed per revolution is calculated in accordance with the linear trend identified from Figure 6.

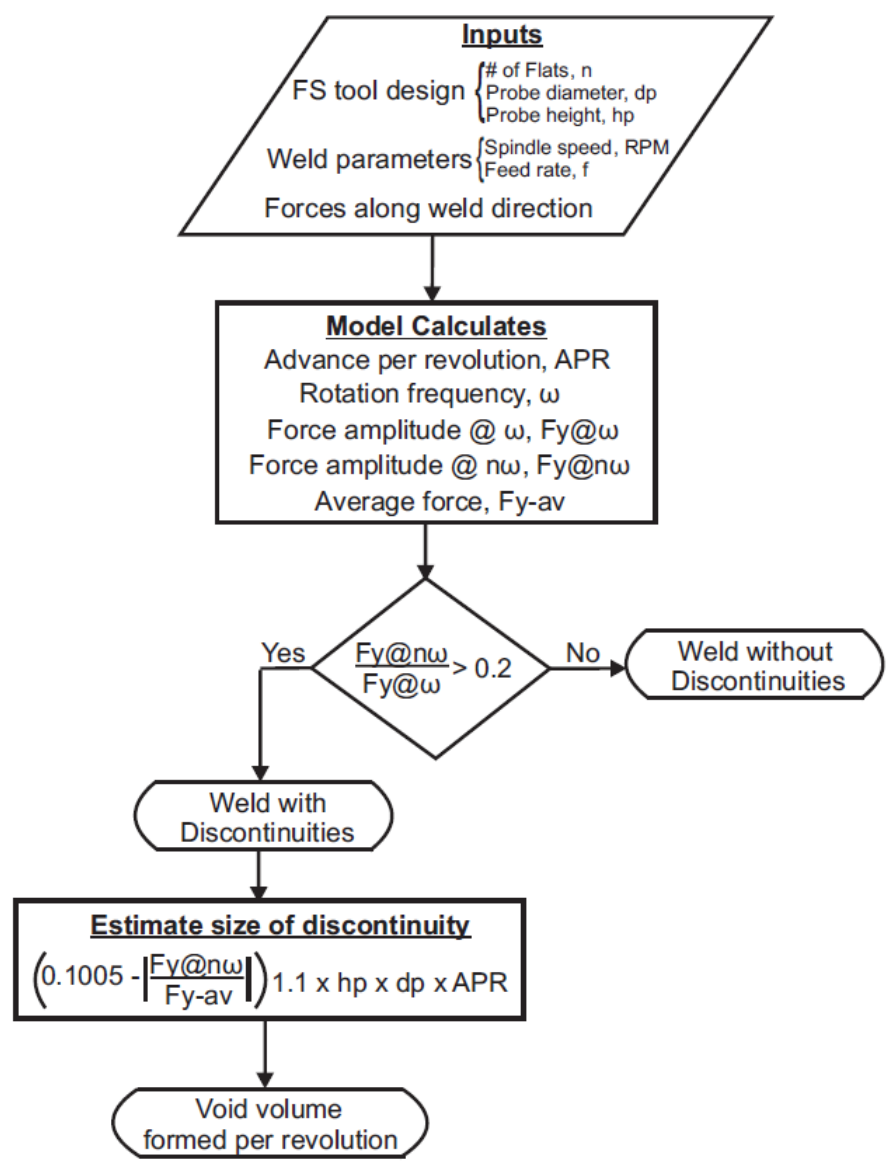

Figure 9: Flowchart of the proposed discontinuity detection and discontinuity size prediction method

Experiments with additional friction stir welds were performed in order to validate the proposed discontinuity method. The RPM, feed rate, workpiece thickness, and tool design (number of flats) were varied in these experiments. The friction stir welds were CT scanned in order to measure the discontinuity sizes. Table 4 shows the weld conditions, measured discontinuity volume per rev, estimated discontinuity volume per revolution, and error for the validation welds. 
Table 4: Weld conditions, measured discontinuity volume per rev, estimated discontinuity volume per revolution, and error for the validation welds

\begin{tabular}{|c|c|c|c|c|c|c|c|}
\hline \multirow[b]{2}{*}{$\begin{array}{c}\text { RPM } \\
\text { (rev/min) }\end{array}$} & \multirow[b]{2}{*}{$\begin{array}{l}\text { Feedrate } \\
\text { (mm/min) }\end{array}$} & \multirow[b]{2}{*}{$\begin{array}{l}\text { No. of FS } \\
\text { Tool Flats }\end{array}$} & \multirow[b]{2}{*}{ 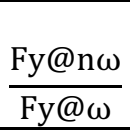 } & \multirow{2}{*}{$\begin{array}{l}\text { Discontinuity } \\
\text { Observed in } \\
\text { Weld? }\end{array}$} & \multicolumn{2}{|c|}{ Discontinuity } & \multirow[b]{2}{*}{$\begin{array}{c}\text { Error } \\
(\%)\end{array}$} \\
\hline & & & & & $\begin{array}{l}\text { Estimated } \\
\left(\mathrm{mm}^{3} / \mathrm{rev}\right)\end{array}$ & $\begin{array}{l}\text { Measured } \\
\left(\mathrm{mm}^{3} / \mathrm{rev}\right)\end{array}$ & \\
\hline 900 & 300 & 3 & 0.03 & No & - & - & - \\
\hline 900 & 350 & 3 & 0.09 & No & - & - & - \\
\hline 900 & 400 & 3 & 0.21 & Yes & 0.92 & 0.96 & 4.2 \\
\hline 900 & 450 & 3 & 0.23 & Yes & 1.24 & 1.18 & 4.6 \\
\hline 900 & 500 & 3 & 0.75 & Yes & 1.19 & 1.30 & 8.9 \\
\hline 1000 & 600 & 3 & 0.86 & Yes & 1.90 & 2.20 & 13.5 \\
\hline 900 & 500 & 2 & 0.82 & Yes & 2.38 & 2.85 & 19.9 \\
\hline
\end{tabular}

A friction stir weld experiment was performed such that the weld parameters were switched from $900 \mathrm{rev} / \mathrm{min}$ (spindle speed) and $500 \mathrm{~mm} / \mathrm{min}$ (feed) to $1000 \mathrm{rev} / \mathrm{min}$ (spindle speed) and $600 \mathrm{~mm} / \mathrm{min}$ (feed) midway (90 mm from beginning of weld) along the weld length $(180 \mathrm{~mm})$. Both sets of parameters are known to create welds with discontinuities. A 45-mm-long CT scan specimen was prepared and was centered at the middle of the weld length. Multiple semicircular ROIs were created such that each ROI covered the material moved in each APR. This configuration was achieved by aligning the ROIs with the features created by the discontinuities in the weld. The discontinuity sizes were measured for each ROI. Figure 10 shows the discontinuity size for each ROI along the length of the CT scan specimen. One can see that the estimated discontinuity size (red line) tracks the measured discontinuity size (blue line) well during the steady state. However, the estimated discontinuity size does not follow the measured discontinuity size during the transition from one set of weld conditions to a second set of weld conditions. Figure 10 shows that approximately 5-7 revolutions were needed for the transition from one set of weld conditions to another. This discrepancy between the measured and estimated discontinuity sizes is tied to the formulation of the discontinuity detection method. The method looks for any deviation from the steady-state behavior and assumes that the deviation is due to the discontinuity formation. However, when weld parameters transition from one set of conditions to another, there will be additional dynamics in the force signal due to the acceleration or deceleration of the tool (in both spindle speed and feed) and $\mathrm{CNC}$ response. 


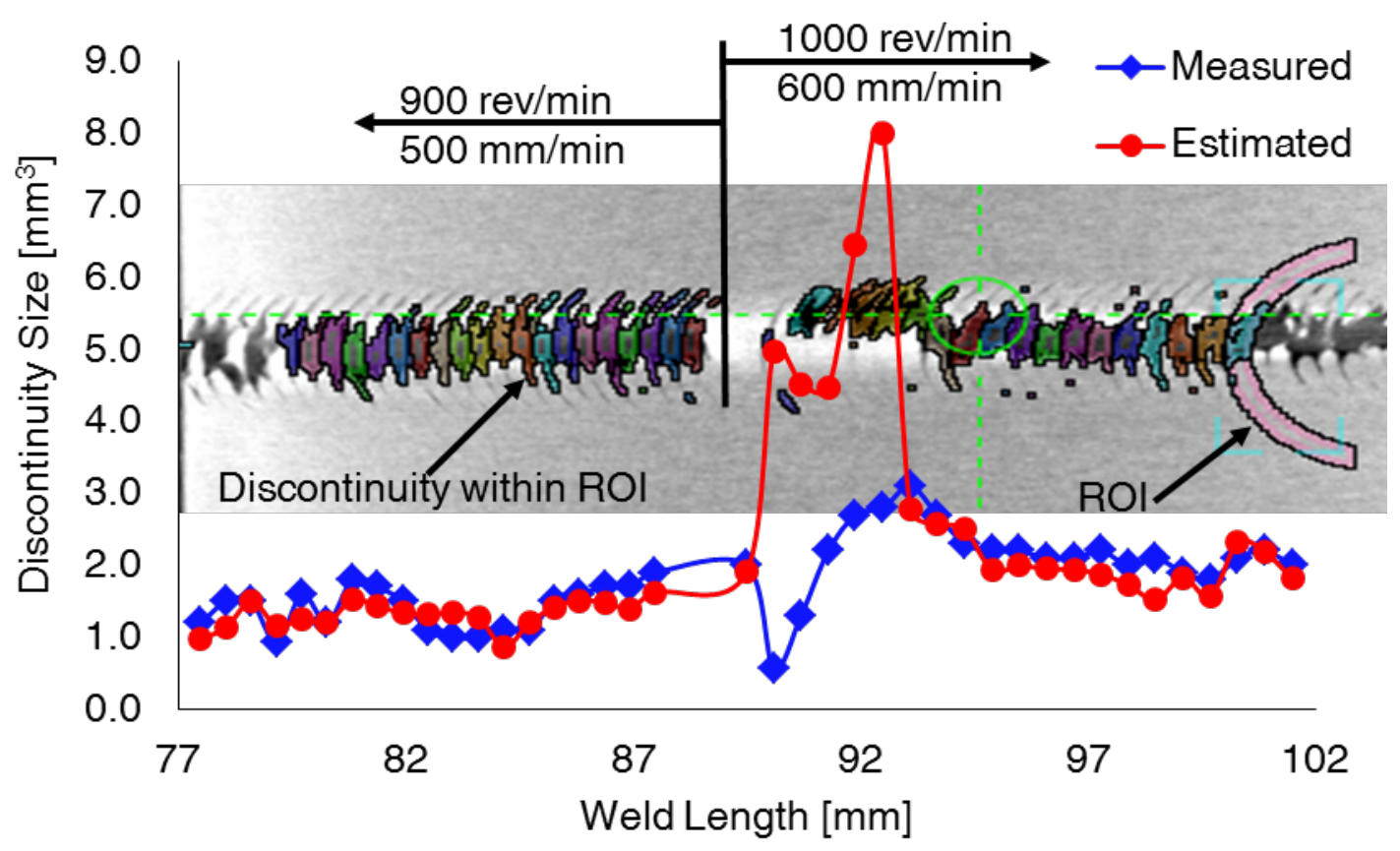

Figure 10: Discontinuity sizes along the weld length as weld parameters change

\subsection{Measurement uncertainties and method limitations}

The force dynamometer, charge amplifier, and data acquisition were identified as the uncertainty sources for the force measurement. An uncertainty of $\pm 9.4 \mathrm{~N}$ was involved with the measurement of the forces in $y$-direction. This uncertainty in force measurement was used to estimate the uncertainty in the normalized forces presented in Figures 5, 6, and 7. The order of uncertainty involved with the normalized forces in Figures 5 and 6 is -3 ; the order of normalized forces in Figures 5 and 6 is -2 ; the order of uncertainty involved with the normalized forces in Figure 7 is -2 ; and the order of normalized forces in Figure 7 is -1 . Therefore, uncertainty involved with the normalized forces is smaller than the magnitudes presented in this work by order of -1 .

A representative CT specimen (with discontinuity) was scanned five times and dark-light calibration was performed for each scan. The discontinuity size measurement had a standard deviation of $0.3 \mathrm{~mm}^{3}$. For the given FS tool dimensions and this standard deviation, the order of the uncertainty involved with the normalized discontinuity volume (Figures 5, 6, and 7) is estimated to be -4 . Some of the normalized discontinuity volume magnitudes have an order of -3 , while the rest have an order of 2. In either case the uncertainty involved with the normalized discontinuity volume is smaller than the magnitudes presented in this work by an order of -1 . For welds without discontinuity, some measurements had the same order as the order of the estimated uncertainty (-4). Thus it could be assumed that the void size given by CT software is essentially measurement uncertainty, and void size could be shown in results as zero $\mathrm{mm}^{3}$. However, no such assumption was made and the void sizes for the welds without discontinuities are presented as such (as given by the CT software).

The uncertainty involved with the force measurement and data acquisition equipment, limits the minimum size of the discontinuity that can be detected by this method. The discontinuity detection method estimates the discontinuity size as the fraction of the stir zone volume (normalized discontinuity size). The stir zone can be assumed as a thin cylinder of material rotating around the FS tool probe. The stir zone volume is estimated from the probe diameter, probe height and APR (feed 
rate/RPM). The uncertainty involved with the normalized forces (discussed above) corresponds to a normalized discontinuity size of 0.003 . For a representative friction stir weld performed with aluminum 6061 at $1000 \mathrm{rpm}$ and $500 \mathrm{~mm} / \mathrm{min}$ (feed), by a FS tool with average probe diameter of $6 \mathrm{~mm}$ and probe height of $5 \mathrm{~mm}$, the normalized discontinuity size represents a total discontinuity volume of $0.14 \mathrm{~mm}^{3}$. Therefore, $0.14 \mathrm{~mm}^{3}$ is the minimum size (volume) of the discontinuity that the proposed discontinuity detection method can detect during a representative friction stir weld. As discussed earlier, discontinuity morphology varies across friction stir welds. However, assuming the discontinuity is not scattered throughout the stir zone volume, the minimum discontinuity width (measured along the weld length) would occur for the case where discontinuity is formed uniformly along the periphery of the FS tool probe. For this case of minimum width of discontinuity, the minimum detectable discontinuity volume of $0.14 \mathrm{~mm}^{3}$ would correspond to a semicircular pore of $0.015 \mathrm{~mm}$ running along the trailing edge of the FS tool. These minimum detectable discontinuity sizes are estimated theoretically and further work is required to confirm the same.

Two particular limitations of the discontinuity detection method have been identified thus far.

1. The proposed method can be used only for FS tools with two or more flats. Figure 11 shows the frequency content of the force data measured during the FSW of a weld performed with an FS tool with only one flat. This weld was performed at conditions known to create a weld with discontinuities (i.e., subsurface voids). A macrograph was made to confirm the presence of discontinuities in the weld. The discontinuity detection method presented in this paper is based on the assumption that the generation of discontinuities is accompanied by force dynamics at a frequency corresponding to the number of flats on the FS tool (number of flat times the tool rotation frequency). These force dynamics occur in addition to the force dynamics associated with cavity formation and filling that occur during every tool rotation, whether a discontinuity remains in the weld of not. The discontinuity detection method relates the additional force dynamics (for welds with discontinuity) with the discontinuity size. However, for a friction stir weld with discontinuities created with the 1-flat FS tool, the additional force dynamics and the regular force dynamics occur at the same (tool rotation) frequency and appear to nullify each other (Figure 11). Hence, the proposed method is inapplicable in the case of FSW with the 1-flat FS tool.

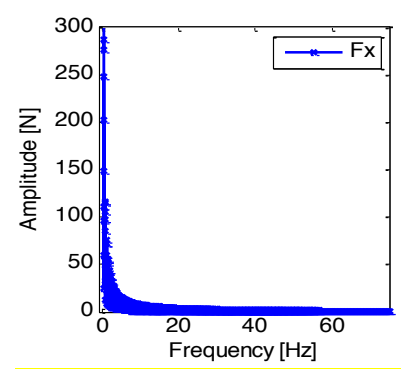

Figure 11: Frequency domain content of $x$-force signal measured during FSW performed with the 1-flat FS tool

2. The proposed discontinuity detection method inaccurately captures the size of the discontinuities during the transition of weld parameters. Figure 10 shows that the estimated discontinuity size does not follow the measured discontinuity sizes during the transition from one set of weld parameters (spindle speed and feed) to another set of conditions. The discontinuity detection method does not account for the additional force dynamics observed during the transition. For such applications a model (in addition to the proposed discontinuity model) needs to be developed that can capture the force dynamics originating from the transition of the weld parameters (acceleration or deceleration of the spindle speed or feed of FS tool). 


\section{Conclusions}

The frequency and time-domain content of process force signals can be correlated to the occurrence and size of discontinuities (i.e., subsurface voids, volume defects) during friction stir welding of 6061-T6 aluminum. One force-signal parameter is needed to predict the onset of a subsurface void, and another is needed to predict the size of the volume defect(s) being generated.

In order to predict the occurrence of a subsurface void, a force parameter is defined based on a ratio of force magnitudes taken from the frequency spectrum of the force signal: amplitude of the third harmonic of the weld-direction force (Fy) divided by the amplitude of the first harmonic of Fy. The third harmonic is used because it corresponds to the number of FS tool flats. This is referred to as a normalized force transient. The force amplitude at the higher harmonic corresponds to the number of flats on the friction stir (FS) tool's probe. The normalized force transient data and normalized discontinuity size were correlated to develop criteria for discontinuity detection and discontinuity estimation. A threshold value of 0.2 for the ratio of the Fy third harmonic (corresponding to number of FS tool flats) amplitude to the Fy first harmonic amplitude was determined for discontinuity detection. If the ratio is smaller than the threshold value, the weld is evaluated as a "weld without discontinuity." Otherwise, the weld is evaluated as a "weld with discontinuity."

In order to predict the total volume of voids formed during FSW, a different parameter was used: the amplitude of the third harmonic of Fy divided by the average Fy force. A linear relationship between this normalized force parameter and discontinuity size normalized by the stir zone volume was determined. This relationship allows the estimation of discontinuity size.

The force-signal parameters were discerned from the force measurements taken during each rotation of the FS tool. The frequency content of the force signal can be calculated with a fast Fourier Transform. The amplitudes of the first and third harmonics (for the FS tool with three flats on its probe) can be pulled from the frequency spectrum. With the proper choice of data acquisition system and frequency analyzer, the occurrence and size of sub-surface voids can be detected in real time, so that corrective actions can be taken.

\section{Acknowledgments}

The authors gratefully acknowledge support of this work by the National Science Foundation (grant CMMI-1332738), the Department of Mechanical Engineering at the University of WisconsinMadison, the Machine Tool Technology Research Foundation, the Small Animal Imaging Facility at the University of Wisconsin Carbone Cancer Center (Cancer Center Support grant P30 CA014520) and colleagues in the Advanced Manufacturing Lab. This work was supported by the U.S. Department of Energy, Office of Science, under Contract DE-AC02-06CH11357.

\section{References}

Boldsaikhan, E., Corwin, E. M., Logar, A. M., and Arbegast, W. J., 2011. The use of neural network and discrete Fourier transform for real-time evaluation of friction stir welding. Applied Soft Computing, 11, pp. 4839-4846.

Burford, D., Boldsaikhan, E., and Wiley, A., 2012. Early detection of volumetric defects using e-NDE during friction stir welding. In Proceedings of the $9^{\text {th }}$ International Friction Stir Welding Symposium, Huntsville, Alabama, TWI. 
Chen, H.-B., Yan, K., Lin, T., Chen, S.-B., Jiang, C.-Y., and Zhao, Y., 2006. The investigation of typical welding defects for 5456 aluminum alloy friction stir welds. Materials Science and Engineering A, 433, pp. 64-69.

Edwards, P. D., and Ramulu, M., 2015. Material flow during friction stir welding of Ti-6Al-4V. Journal of Materials Processing Technology, 218, pp. 107-115.

Fleming, P., Lammlein, D., Wilkes, D., Fleming, K., Bloodworth, T., Cook, G., Strauss, A., DeLapp, D., Lienert, T., Bement, M., and Prater, T., 2008. In-process gap detection in friction stir welding. Sensor Review, 28(1), pp. 62-67.

Khan, N. Z., Siddiquee, A. N., Khan, Z. A., and Shihab, S. K., 2015. Investigations on tunneling and kissing bond defects in FSW joints for dissimilar aluminum alloys. Journal of Alloys Compounds, 648, pp. 360-367.

Kumar, U., Yadav, I., Kumari, S., Kumari, K., Ranjan, N., Kesharwani, R. K., Jain, R., Kumar, S., Pal, S., Chakravarty, D., and Pal, S. K., 2015. Defect identification in friction stir welding using discrete wavelet analysis. Advances in Engineering Software, 85, pp. 43-50.

Mishra, R. S., and Ma, Z. Y., 2005. Friction Stir Welding and Processing. Materials Science and Engineering, R 50, pp. 1-78.

Morisada, Y., Imaizumi, T., and Fujii, H., 2015. Clarification of material flow and defect formation during friction stir welding. Science and Technology of Welding and Joining, 20(2), pp. 130-137.

Ramulu, P. J., Narayanan, R. G., Kailas, S. V., and Reddy, J., 2013. Internal defects and process parameter analysis during friction stir welding of Al 6061 sheets. International Journal of Advanced Manufacturing Technology, 65, pp. 1515-1528.

Rosado, L. S., Santos, T. G., Piedade, M., Ramos, P. M., and Vilaça, P., 2010. Advanced technique for non-destructive testing of friction stir welding of metals. Measurement, 43, pp. 1021-1030.

Santos, T. G., Miranda, R. M., and Vilaça, P., 2014. Friction stir welding assisted by electric Joule effect. Journal of Materials Processing Technology, 214, pp. 2127-2133.

Shrivastava, A., Pfefferkorn, F. E., Duffie, N. A., Ferrier, N. J., Smith, C. B., Malukhin, K., and Zinn, M., 2015. Physics-based process model approach for detecting discontinuity during friction stir welding. International Journal of Advanced Manufacturing Technology, 79, pp. 604-615.

Singh, K., and Hamilton, C., 2009. Developing predictive tools for friction stir weld quality assessment. In Proceedings of the $16^{\text {th }}$ International Congress on Sound and Vibration, Krakow, Poland.

Thomas, W. M., Nicholas, E. D., Needham, J. C., Murch, M. G., Temple-Smith, P., and Dawes, C. J., 1991. Friction-stir butt welding. Great Britain Patent, No. 9125978.8.

Thomas, W. M., Nicholas, E. D., Needham, J. C., Murch, M. G., Temple-Smith, P., and Dawes, C. J., 1995. Improvements Relating to Friction Stir Welding. European Patent, No. EP0615480.

Threadgill, P. L., Leonard, A. J., Shercliff, H. R., and Withers, P. J., 2009. Friction stir welding of aluminium alloys. International Materials Reviews, 54(2), pp. 49-93.

Yasui, T., Ishida, S., and Fukumoto, M., 2014. Material flow observation for dissimilar friction stir welding of aluminum alloy and steel by X-ray CT method. Journal of Japan Institute of Light Metals, 64(11), pp. 604-610.

Zhang, H., and Liu, H., 2012. Characteristics and formation mechanisms of welding defects in underwater friction stir welded aluminum alloy. Metallography, Microstructure, and Analysis, 1, pp. 269-281. 


\section{Government License:}

The submitted manuscript has been created by UChicago Argonne, LLC, Operator of Argonne National Laboratory ("Argonne"). Argonne, a U.S. Department of Energy Office of Science laboratory, is operated under Contract No. DE-AC02-06CH11357. The U.S. Government retains for itself, and others acting on its behalf, a paid-up nonexclusive, irrevocable worldwide license in said article to reproduce, prepare derivative works, distribute copies to the public, and perform publicly and display publicly, by or on behalf of the Government. 


\section{Vertical force}

FSW Tool

Retreating Side

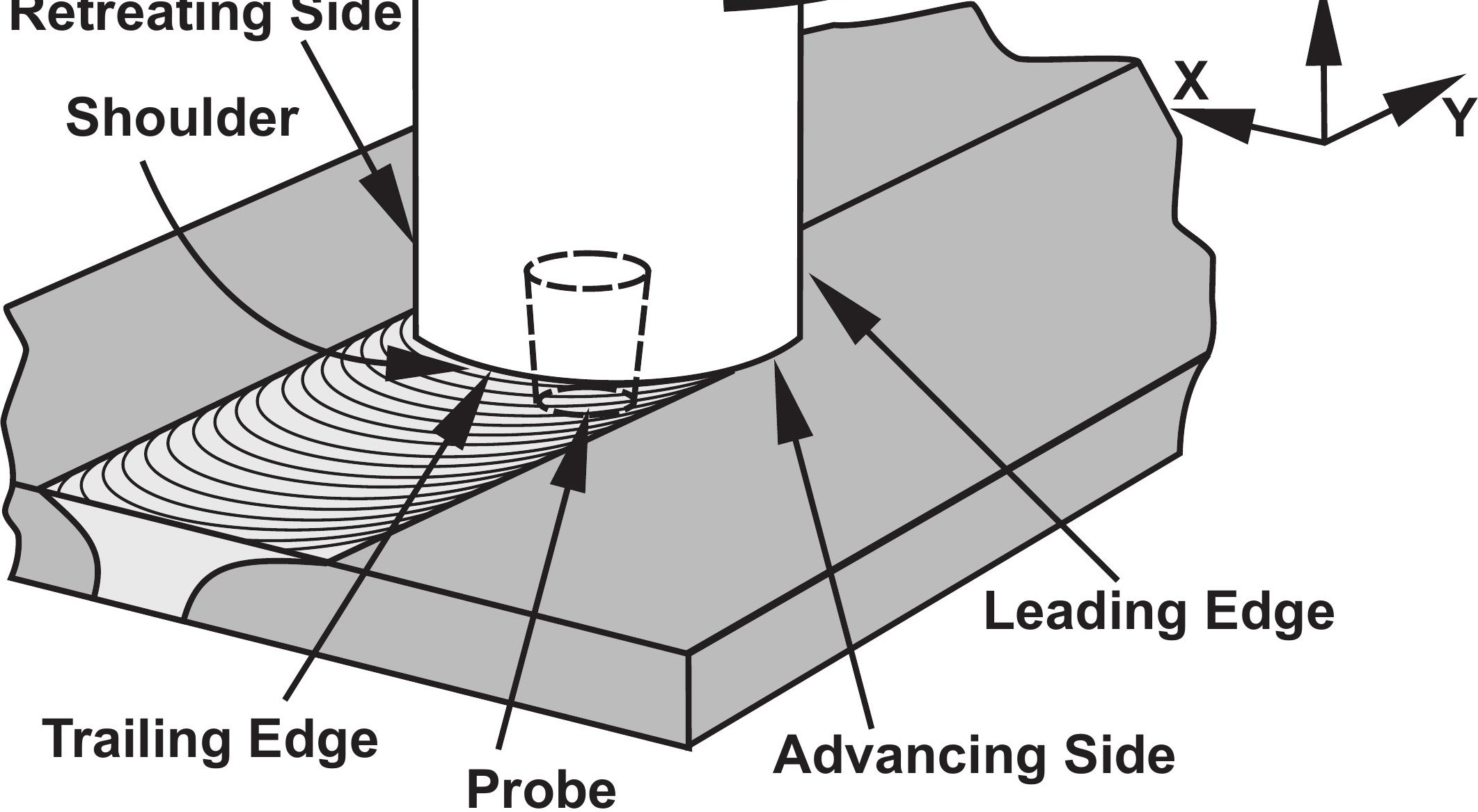

\section{Advancing Side}




\section{$45 \mathrm{~mm}$}

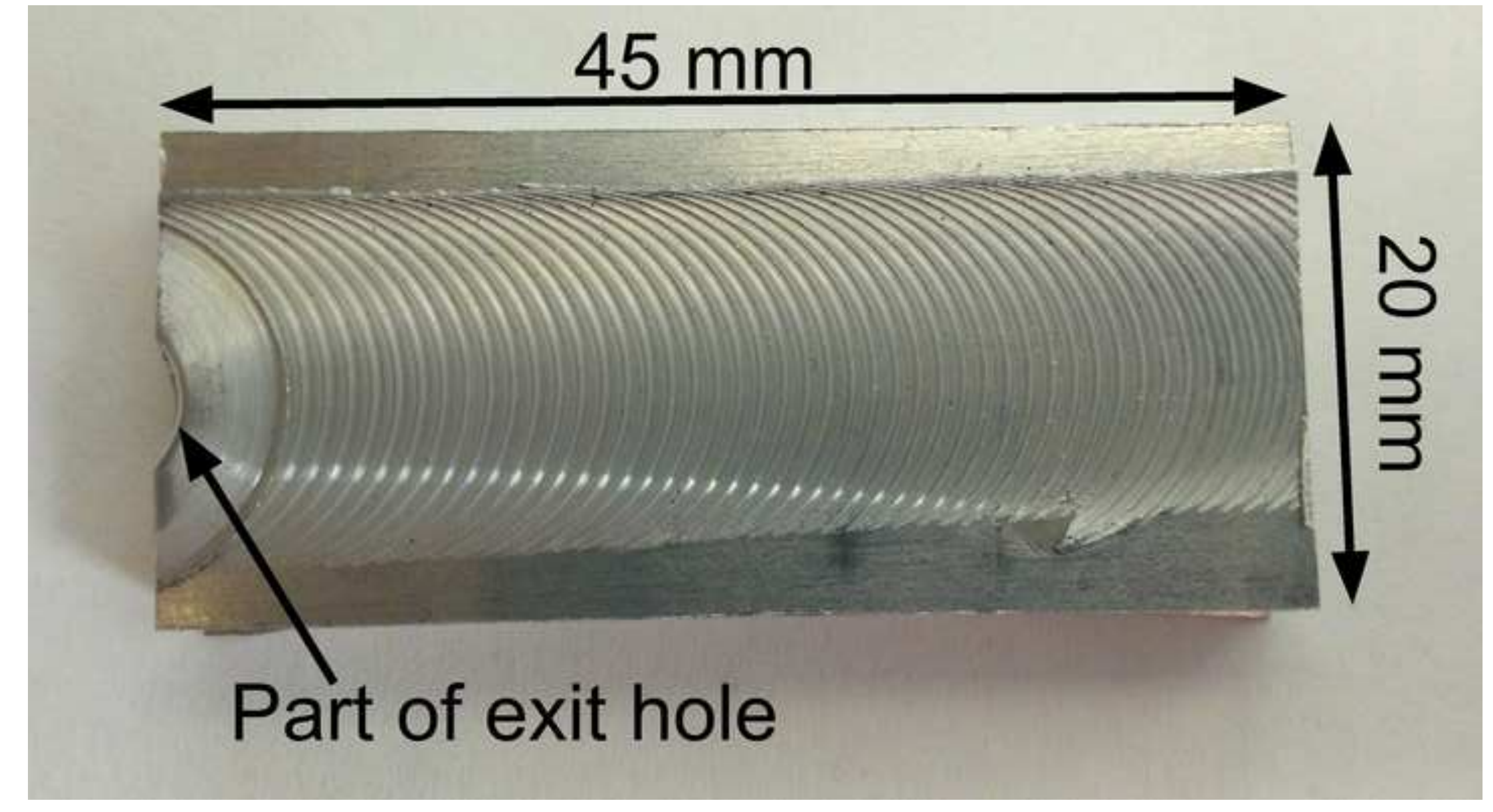




\section{Last shoulder diameter mark}

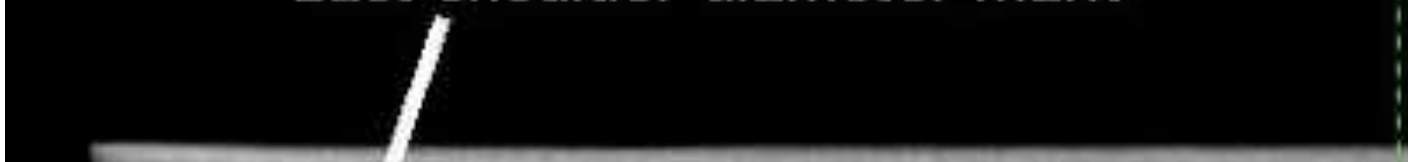

L

R2: 5.027mm R3: 20.00mm

$5 \mathrm{~mm}$ gap from

$20 \mathrm{~mm}$ long $\mathrm{ROI}$ last shoulder mark 


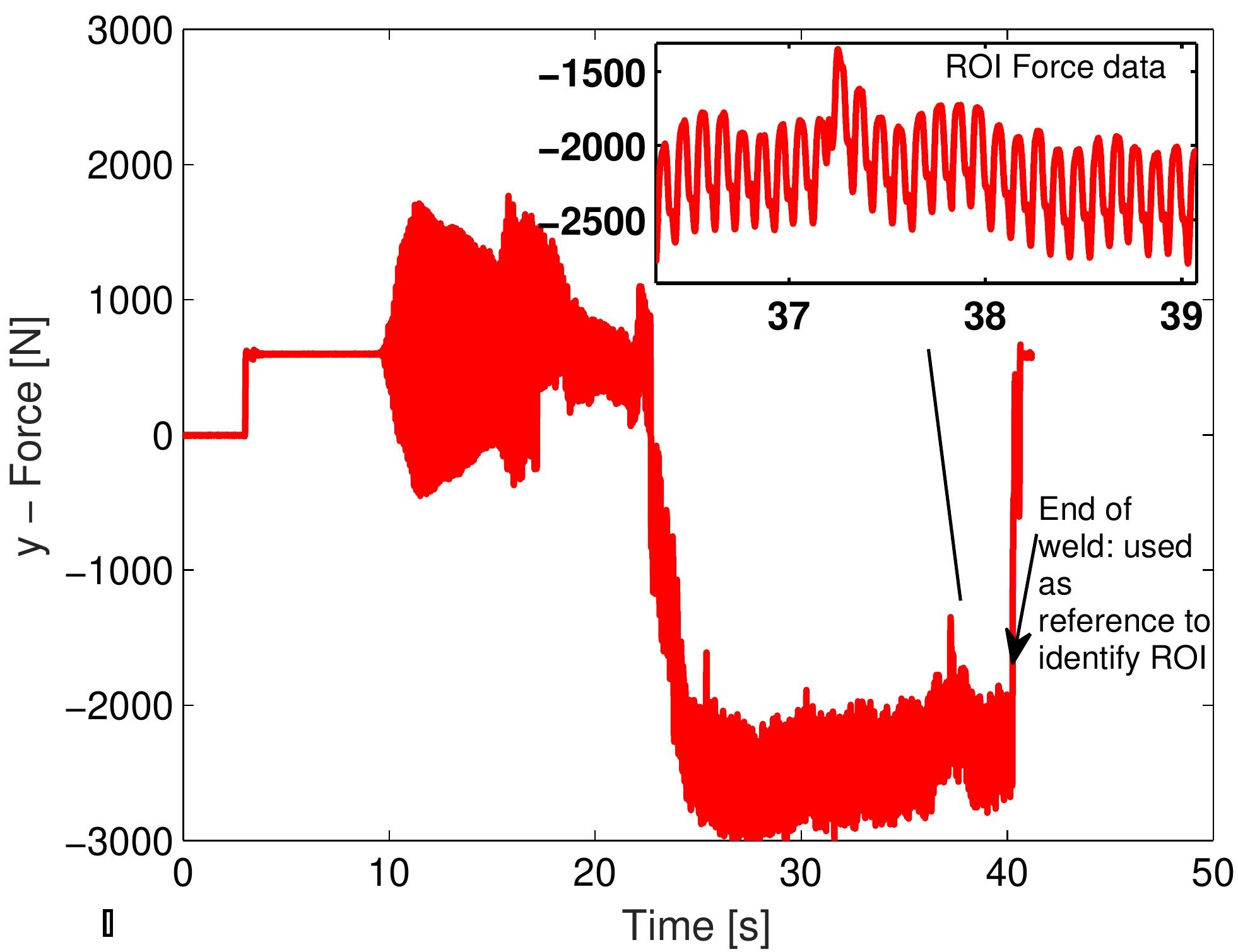




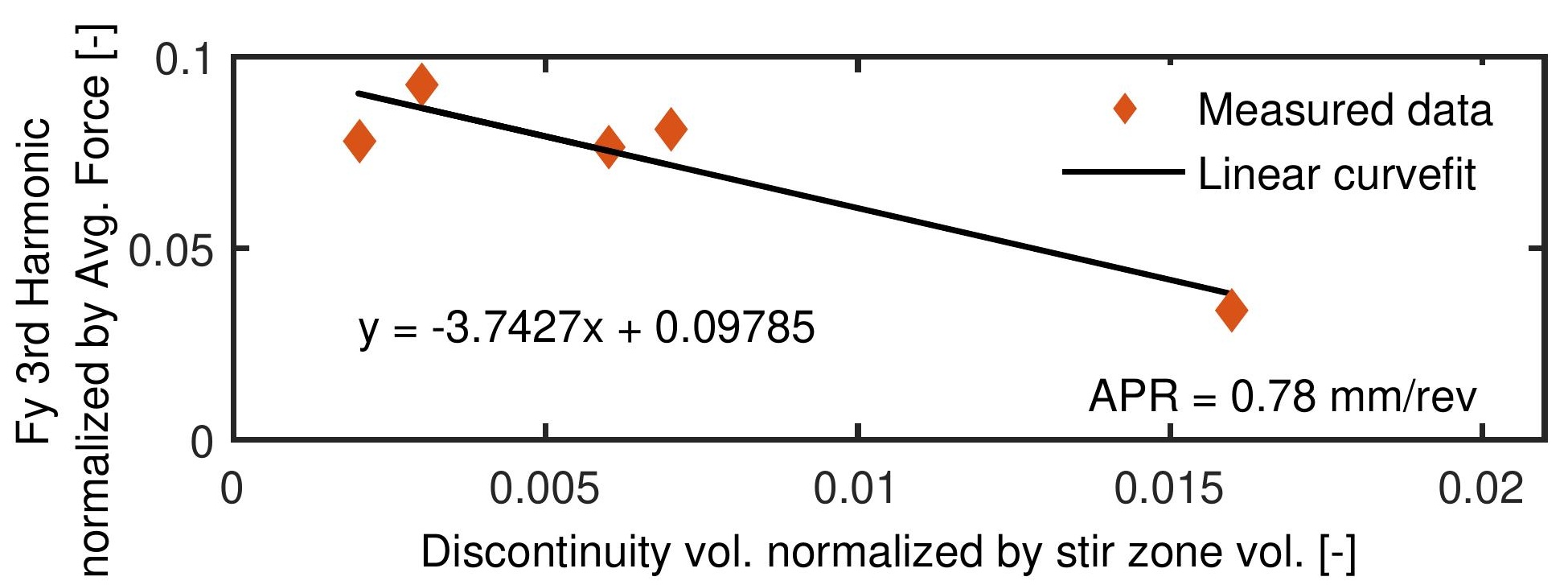

Figure 5a 
Figure 5c

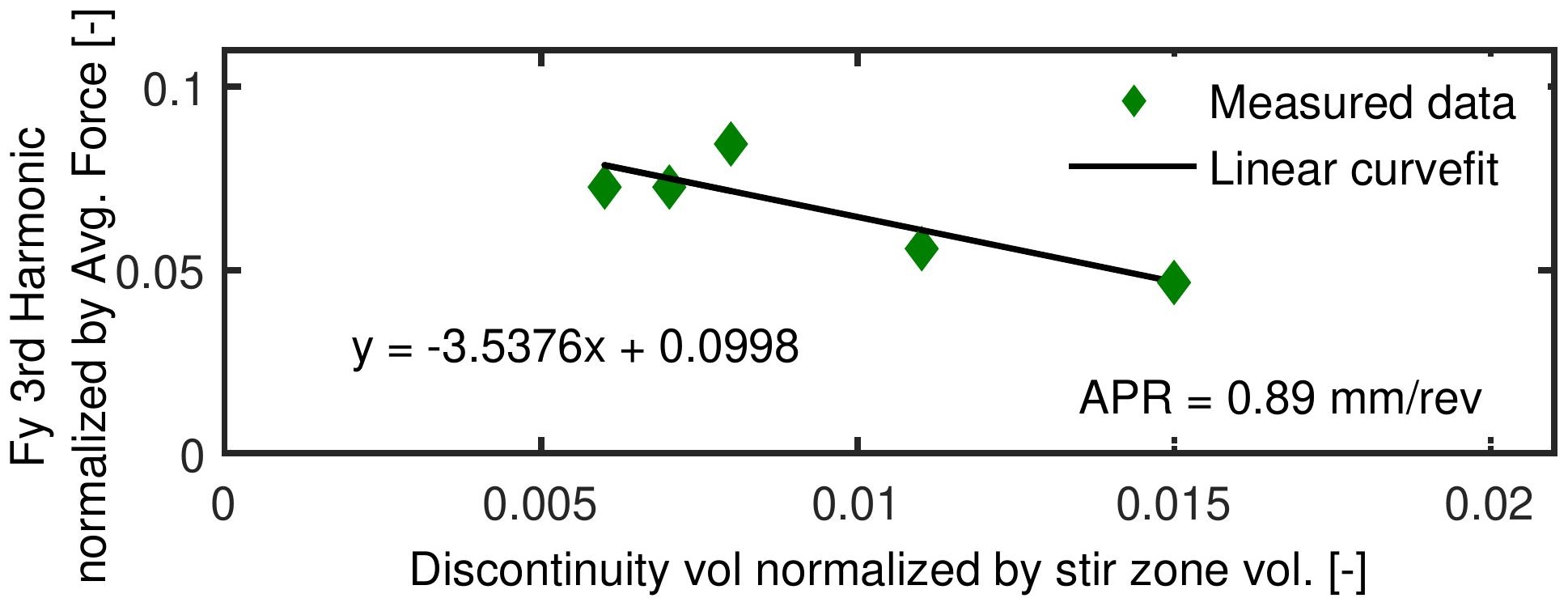


Figure 5e

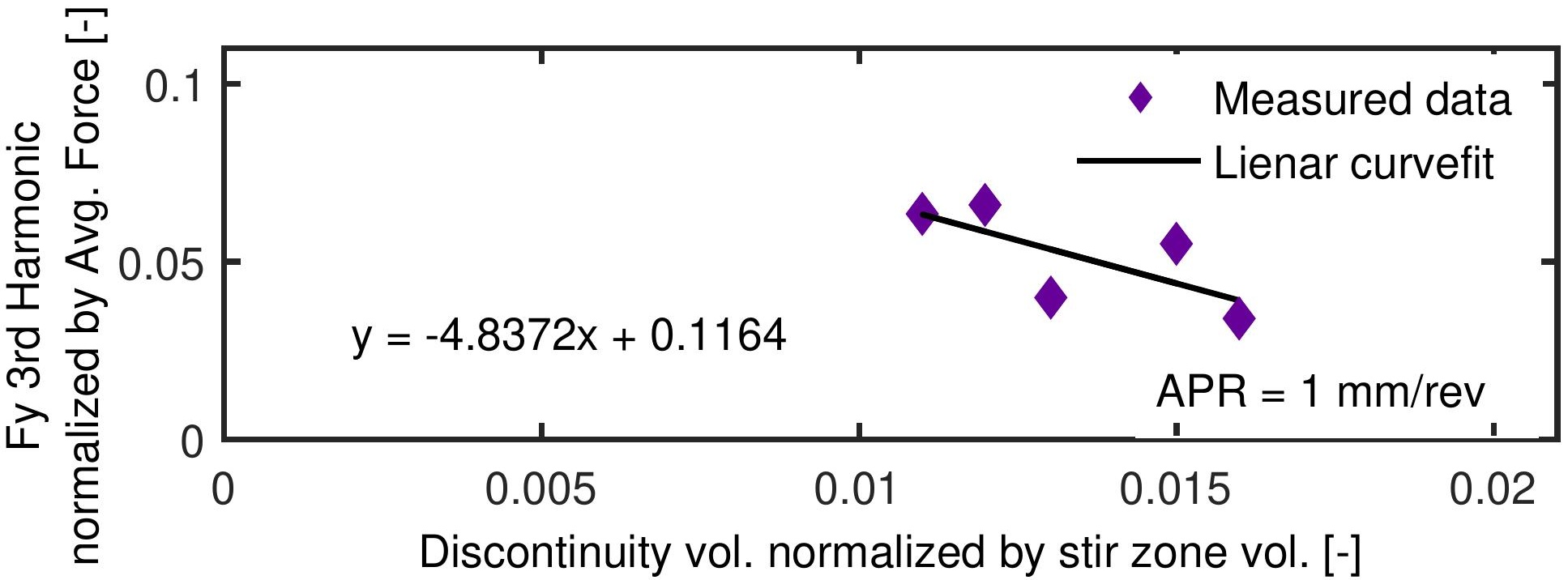

\footnotetext{
Discontinuity vol. normalized by stir zone vol. [-]
} 


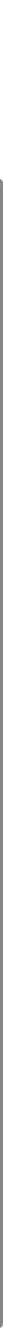

Figure 7

Figure 7

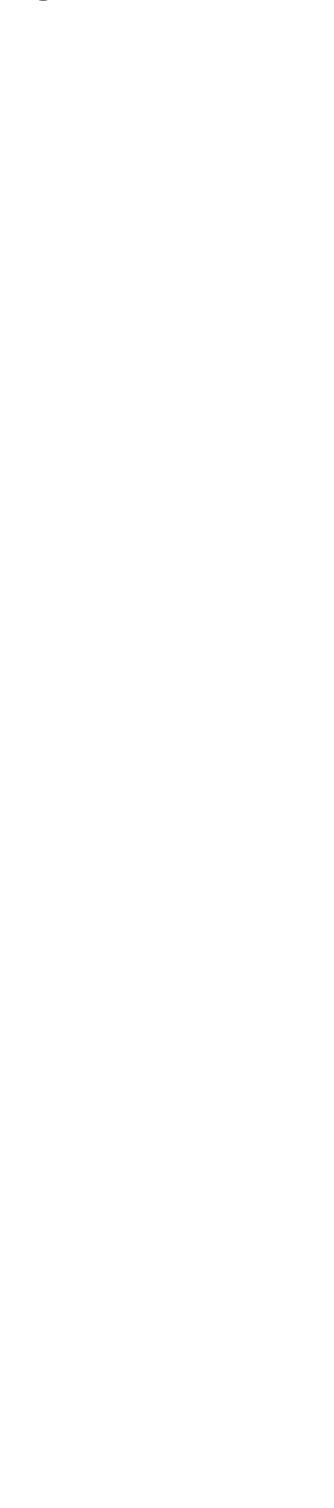




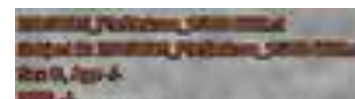

encis

mopestines

pa

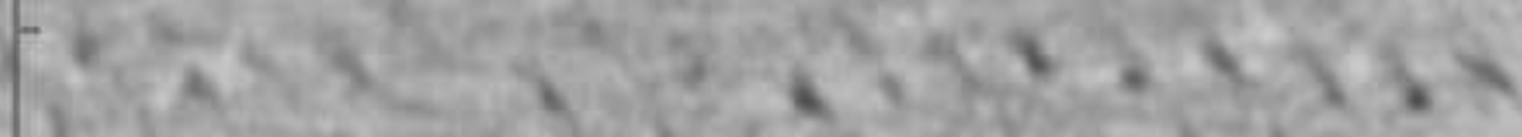

Dinssosusting

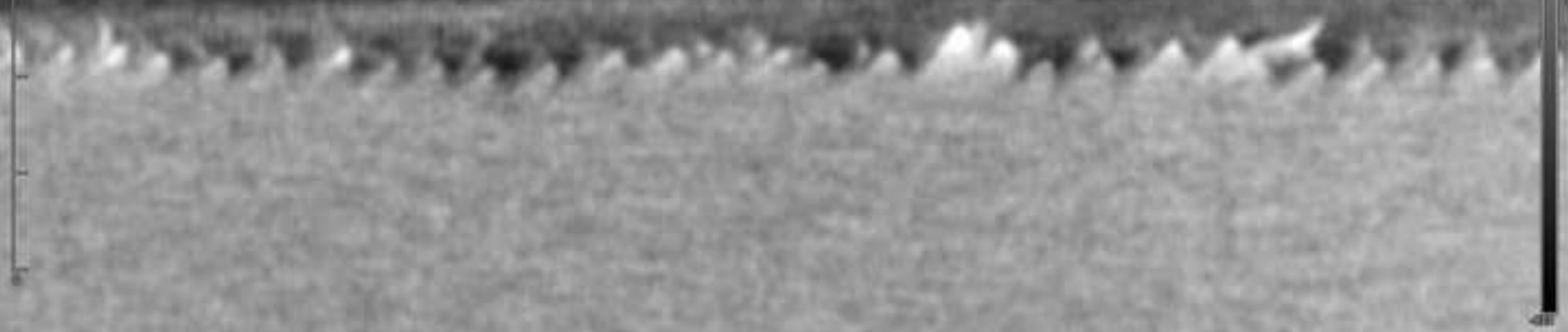




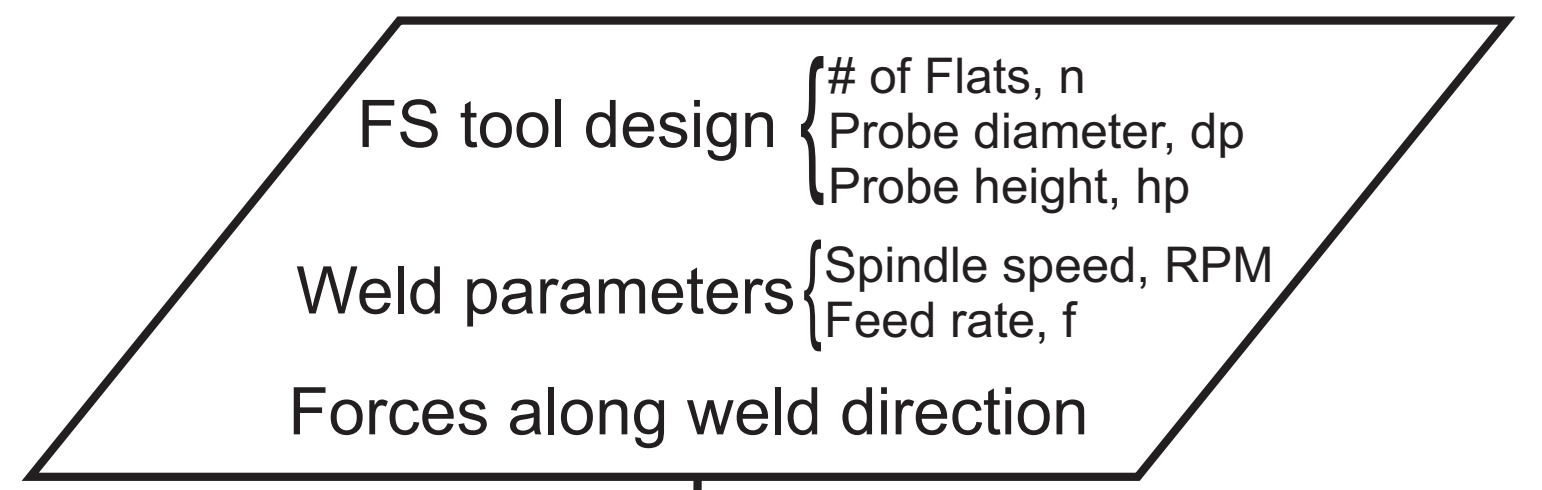

Advance per revolution, APR

Rotation frequency, $\omega$

Force amplitude @w, Fy@w

Force amplitude@nw, Fy@nw

Average force, Fy-av

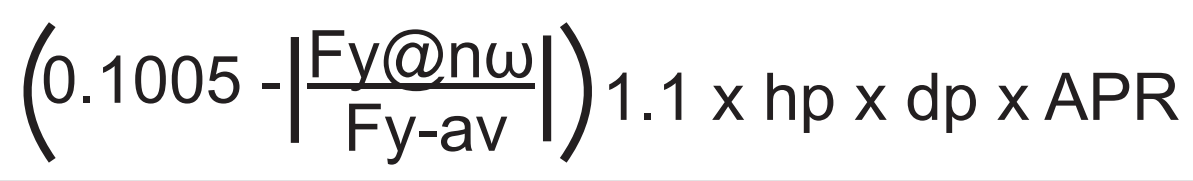

Void volume

formed per revolution 


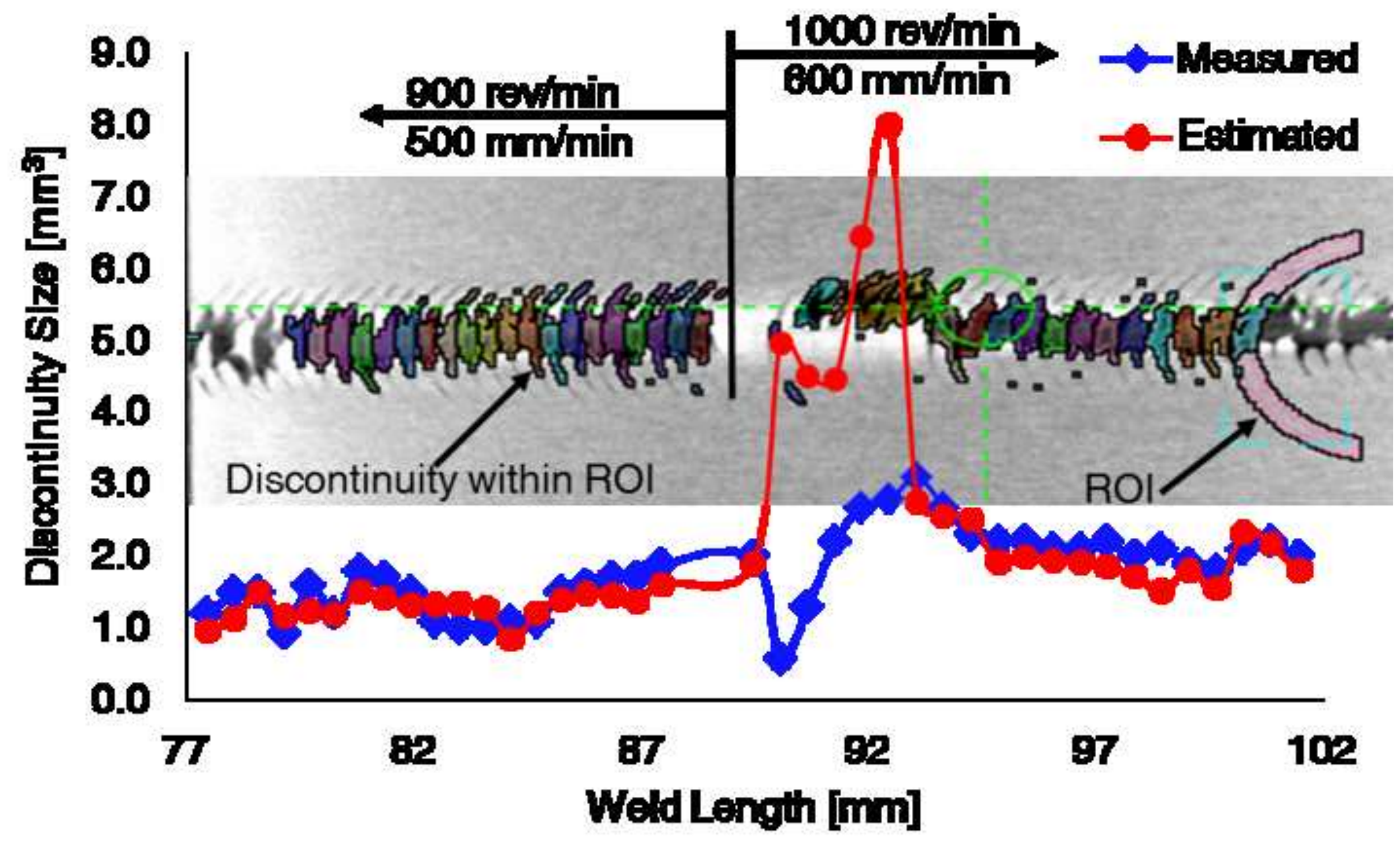




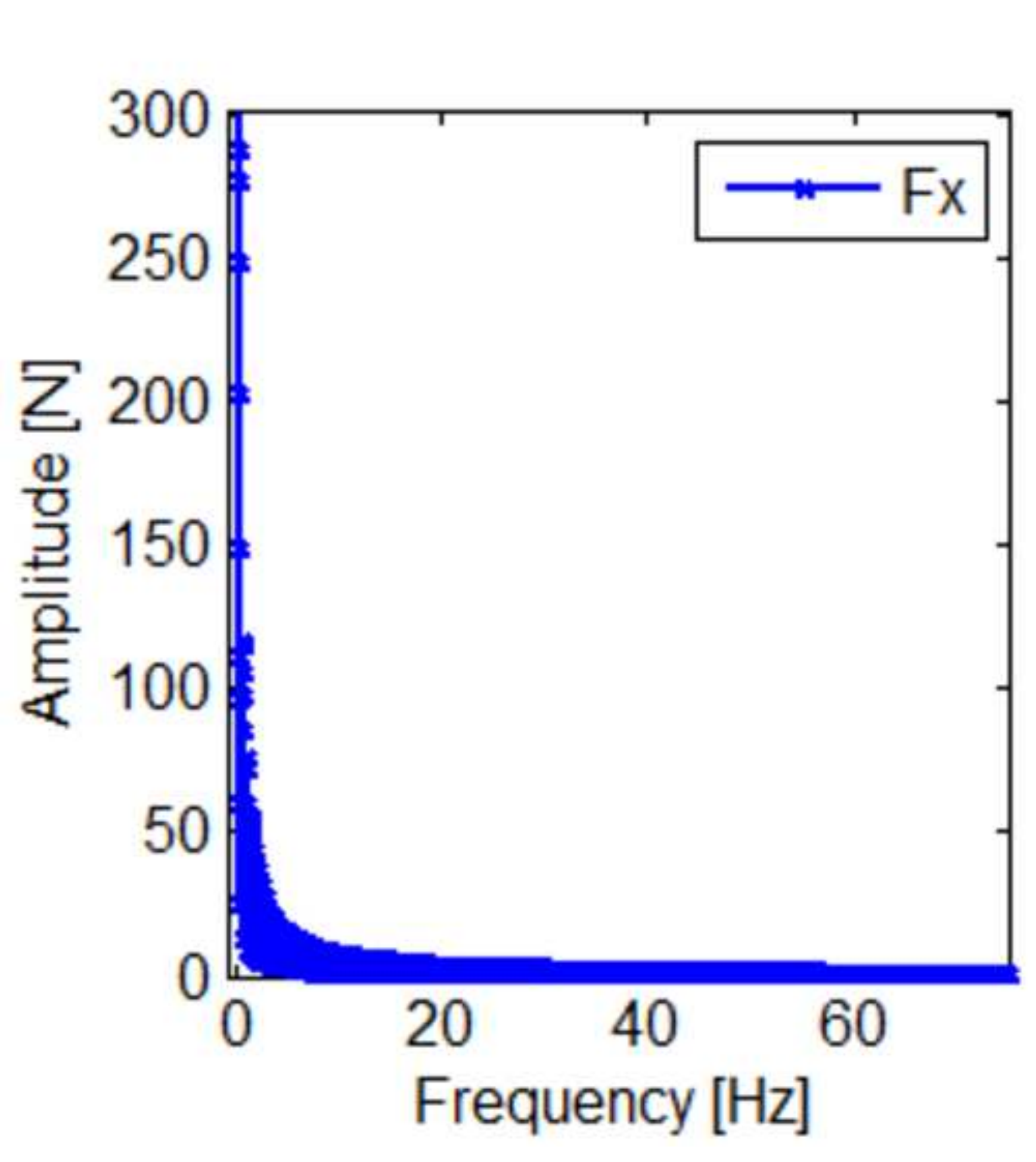

Figure 11

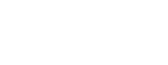

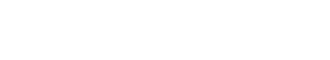

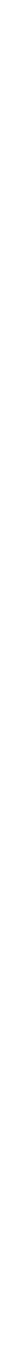

